\title{
Desmídias (Zygnemaphyceae) do Rio São João, Parque Nacional do Iguaçu, Paraná, Brasil
}

\author{
Jascieli Carla Bortolini ${ }^{1}$, Thamis Meurer ${ }^{1}$ e Norma Catarina Bueno ${ }^{2,3}$
}

Recebido: 13.08.2009; aceito: 13.05.2010

\begin{abstract}
Desmids (Zygnemaphyceae) of the São João River, Iguaçu National Park, Paraná, Brazil). This paper is a characterization of the desmid florula of the São João River, Iguaçu National Park, Foz do Iguaçu, Paraná, Brazil. Samples were collected in the period from June 2008 to May 2009 in three sampling stations of the São João river. The samples were obtained with a $25 \mu \mathrm{m}$ nylon plankton net was immediately fixed on Transeau solution. 44 taxa were identified distributed among the genera Actinotaenium (1), Bambusina (1), Closterium (7), Cosmarium (11), Desmidium (1), Euastrum (2), Gonatozygon (3), Micrasterias (5), Netrium (1), Octacanthium (1), Pleurotaenium (1), Spondylosium (2), Staurastrum (4), Staurodesmus (2), Teilingia (1), and Xanthidium (1). Cosmarium Corda ex Ralfs was the most representative genus in the study, with $25 \%$ of the local documented taxa.
\end{abstract}

Key words: desmids, river, taxonomy, Zygnemaphyceae

RESUMO - (Desmídias (Zygnemaphyceae) do Rio São João, Parque Nacional do Iguaçu, Paraná, Brasil). O presente trabalho é a identificação da desmidioflórula do Rio São João, Parque Nacional do Iguaçu, Foz do Iguaçu, Paraná, Brasil. As amostras foram coletadas no período de junho de 2008 a maio de 2009, em três estações de amostragem do rio São João. As amostras analisadas, coletadas com rede de plâncton com abertura de malha de $25 \mu \mathrm{m}$ foram imediatamente fixadas em solução de Transeau. Foram identificados 44 táxons distribuídos nos gêneros Actinotaenium (1), Bambusina (1), Closterium (7), Cosmarium (11), Desmidium (1), Euastrum (2), Gonatozygon (3), Micrasterias (5), Netrium (1), Octacanthium (1), Pleurotaenium (1), Spondylosium (2), Staurastrum (4), Staurodesmus (2), Teilingia (1), Xanthidium (1). Cosmarium Corda ex Ralfs foi o gênero que obteve maior representatividade no estudo, com $25 \%$ dos táxons documentados para o local.

Palavras-chave: desmídias, rio, taxonomia, Zygnemaphyceae

\section{Introdução}

Estudos taxonômicos de fitoplâncton de ambientes lóticos no Brasil ainda são escassos quando comparados com ambientes lênticos (Soares et al. 2007), sendo que os estudos realizados abrangem em sua maioria a flora diatomológica. No Estado do Rio Grande do Sul, por exemplo, Sophia et al. (2005) em suas amostragens em ambientes lênticos e lóticos totalizaram 38 táxons de desmídias, no entanto, além da comunidade fitoplanctônica abrangeram também a comunidade perifítica e metafítica. Em Minas Gerais Soares et al. (2007) realizaram um levantamento taxonômico da flora fitoplanctônica em dois rios documentando 17 táxons de desmídias. Cavati
\& Fernandes (2008) ao estudarem a comunidade perifítica de dois ambientes no Espírito Santo, sendo um deles lótico, registraram 27 táxons de desmídias. Já Melo et al. (2009) na região amazônica registraram cinco táxons do gênero Euastrum e sete do gênero Micrasterias em um estudo de dois ambientes de águas pretas, sendo um deles o rio Negro.

O conhecimento taxonômico sobre a desmidioflórula paranaense ainda é incipiente, resumindo-se apenas a onze trabalhos, dos quais apenas quatro são para ecossistemas lóticos e exclusivamente para o Rio Tibagi, localizado na porção nordeste do Estado do Paraná. São eles: BittencourtOliveira (1993a) com 23 táxons de desmídias filamentosas, incluindo os gêneros Gonatozygon,

1. Programa de Pós-graduação em Recursos Pesqueiros e Engenharia de Pesca, Universidade Estadual do Oeste do Paraná

2. Universidade Estadual do Oeste do Paraná, Rua da Faculdade 645, Bloco C, Jardim La Salle, 85903-000 Toledo, Paraná, Brasil

3. Autor para correspondência: ncbueno@unioeste.br 
Penium, Pleurotaenium e Tetmemorus; BittencourtOliveira (1993b) que tratou do estudo de 22 táxons de desmídias, incluindo os gêneros Actinotaenium, Cosmarium e Staurodesmus; Bittencourt-Oliveira \& Castro (1993) que realizaram o levantamento de 21 táxons de Closterium e finalmente BittencourtOliveira \& Mecenas (1994) que tratou do estudo dos gêneros Micrasterias, Staurastrum e Xanthidium, totalizando 32 táxons, desses $27(84,4 \%)$ sendo novas citações para o Estado do Paraná.

Os demais estudos registraram a classe Zygnemaphyceae em ambientes lênticos, dos quais incluem Cecy (1993) com Pleurotaenium eherenbergii (Bréb.) De Bary em uma área de restinga em Paranaguá; Cecy et al. (1997) e Picelli-Vicentim et al. (2001) com 40 e 21 táxons de desmídias respectivamente, para a Represa do Passaúna; Silva \& Cecy (2004) com 20 táxons de Cosmarium para a área de abrangência da Usina Hidrelétrica de Salto Caxias; Felisberto \& Rodrigues (2007) com 23 táxons de Closterium para o Reservatório de Salto do Vau; Biolo et al. (2008) com 41 táxons de desmídias para o Reservatório de Itaipu; Felisberto \& Rodrigues (2008) com 45 táxons para o Reservatório de Salto do Vau; Moresco et al. (2009) com nove táxons de Micrasterias e Bortolini et al. (2009) com 17 táxons de Closterium, ambos para o Lago Municipal de Cascavel.

Estudos como os de Andrade \& Rachou (1954), Lozovei \& Luz (1976), Cecy et al. (1976), Lozovei \& Hohmann (1977), Stankiewicz (1980), Stankiewicz et al. (1981), Cecy (1986), Felisberto (2003), Cetto et al. (2004) e Borges et al. (2008) apresentam alguns táxons de desmídias, porém apenas em listagens de cunho ecológico.

$\mathrm{O}$ presente trabalho objetivou o inventário florístico da desmidioflórula do Rio São João, Parque Nacional do Iguaçu, contribuindo com estudos da biodiversidade ficológica de ambientes lóticos do Estado do Paraná.

\section{Material e métodos}

O Rio São João $\left(25^{\circ} 37^{\prime} 27^{\prime}\right.$ 'S e $\left.54^{\circ} 28^{\prime} 03^{\prime \prime} W\right)$ faz divisa a oeste com o Parque Nacional do Iguaçu (PNI), tendo sua foz ligada ao rio Iguaçu (Salamuni et al. 2002). Nasce no Município de Santa Terezinha de Itaipu, desenvolvendo seu curso d'água no sentido norte-sul, com uma área total de cerca de $79,10 \mathrm{~km}^{2}$, dos quais 27,86 km² no Município de Santa Terezinha de Itaipu e $51,23 \mathrm{~km}^{2}$ em Foz do Iguaçu, e destes,
28,09 km2 são pertencentes à área do PNI.

As amostras foram coletadas mensalmente no período de junho de 2008 a maio de 2009 em três estações de amostragem em secção longitudinal (Estação 1: $25^{\circ} 37^{\prime} 14^{\prime \prime}$ S e $54^{\circ} 28^{\prime} 13^{\prime \prime} \mathrm{W}$; Estação 2:

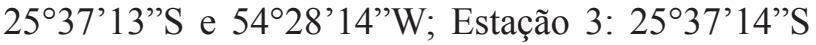
e $54^{\circ} 28^{\prime} 33^{\prime \prime} \mathrm{W}$ ) (figura 1) ao longo do curso do rio, totalizando 36 amostras, as quais se encontram depositadas no Herbário da Universidade Estadual do Oeste do Paraná (UNOP). A estação 1 caracteriza-se pela presença de diversas macrófitas aquáticas, sendo que as estações 2 e 3 são áreas com maior fluxo de correnteza e sem plantas aquáticas.

O material amostrado foi obtido com rede de plâncton com malha de $25 \mu \mathrm{m}$ de abertura e imediatamente preservado em solução Transeau, na proporção 1:1 (Bicudo \& Menezes 2006). Para as análises qualitativas foram preparadas lâminas temporárias, em média 10 lâminas por amostra ou até não ocorrerem táxons diferentes. A análise das lâminas e as ilustrações botânicas foram realizadas com microscópio binocular acoplado com câmara clara em aumentos de 400 e $1000 \times$. As medidas (em $\mu \mathrm{m}$ ) estão representadas pelos símbolos: diâm. = diâmetro; compr. = comprimento; larg. = largura; esp. $=$ espinho; proc. $=$ processo; istmo $=$ istmo .

\section{Resultados e Discussão}

O levantamento taxonômico das desmídias do Rio São João permitiu a identificação de 44 táxons distribuídos nos seguintes gêneros: Actinotaenium (1), Bambusina (1), Closterium (7), Cosmarium (11), Desmidium (1), Euastrum (2), Gonatozygon (3), Micrasterias (5), Netrium (1), Octacanthium (1), Pleurotaenium (1), Spondylosium (2), Staurastrum (4), Staurodesmus (2), Teilingia (1) e Xanthidium (1).

\section{Actinotaenium (Nägeli) Teiling}

Actinotaenium globosum (Bulnheim) Förster ex Compère Bull. Jard. Bot. Natl. Belg. 46: 456. 1976 $\equiv$ Cosmarium globosum Bulnheim, Hedwigia 2: 52. 1861.

Figura 2

Célula 1,3-1,4 vezes mais longa que larga, 4142,6 $\mu \mathrm{m}$ compr., 28,7-32,8 $\mu \mathrm{m}$ larg., 25,4-29,5 $\mu \mathrm{m}$ istmo, margens laterais e ápices arredondados, lisos, constrição mediana rasa, seno mediano fechado, parede celular pontuada, cloroplasto em forma de cristas, 1 pirenóide por semicélula. 

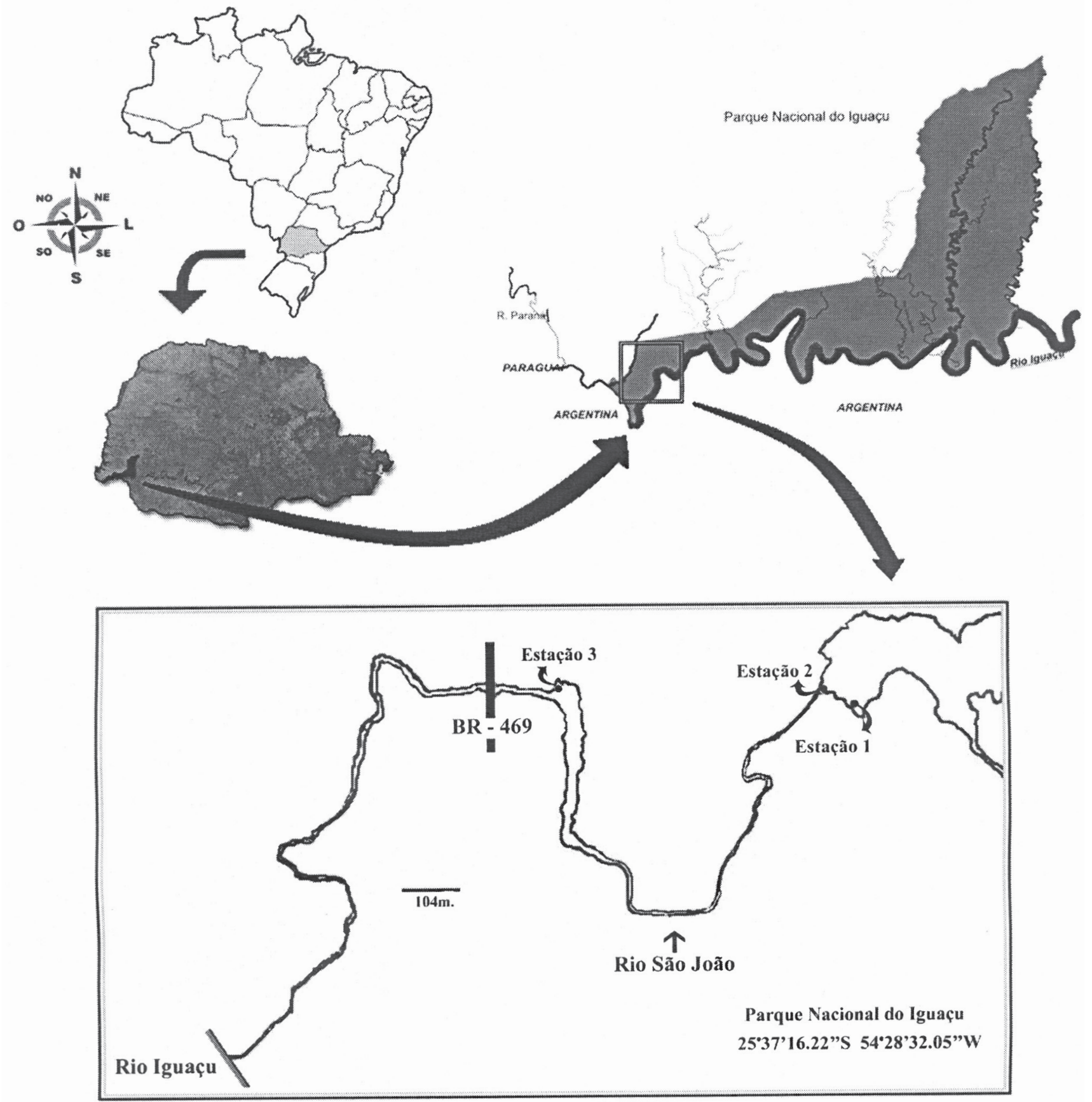

Figura 1. Localização do Rio São João, Parque Nacional do Iguaçu, Foz do Iguaçu, Paraná, Brasil. Figure 1. Location of the São João River, Iguaçu National Park, Foz do Iguaçu, Paraná, Brazil. 

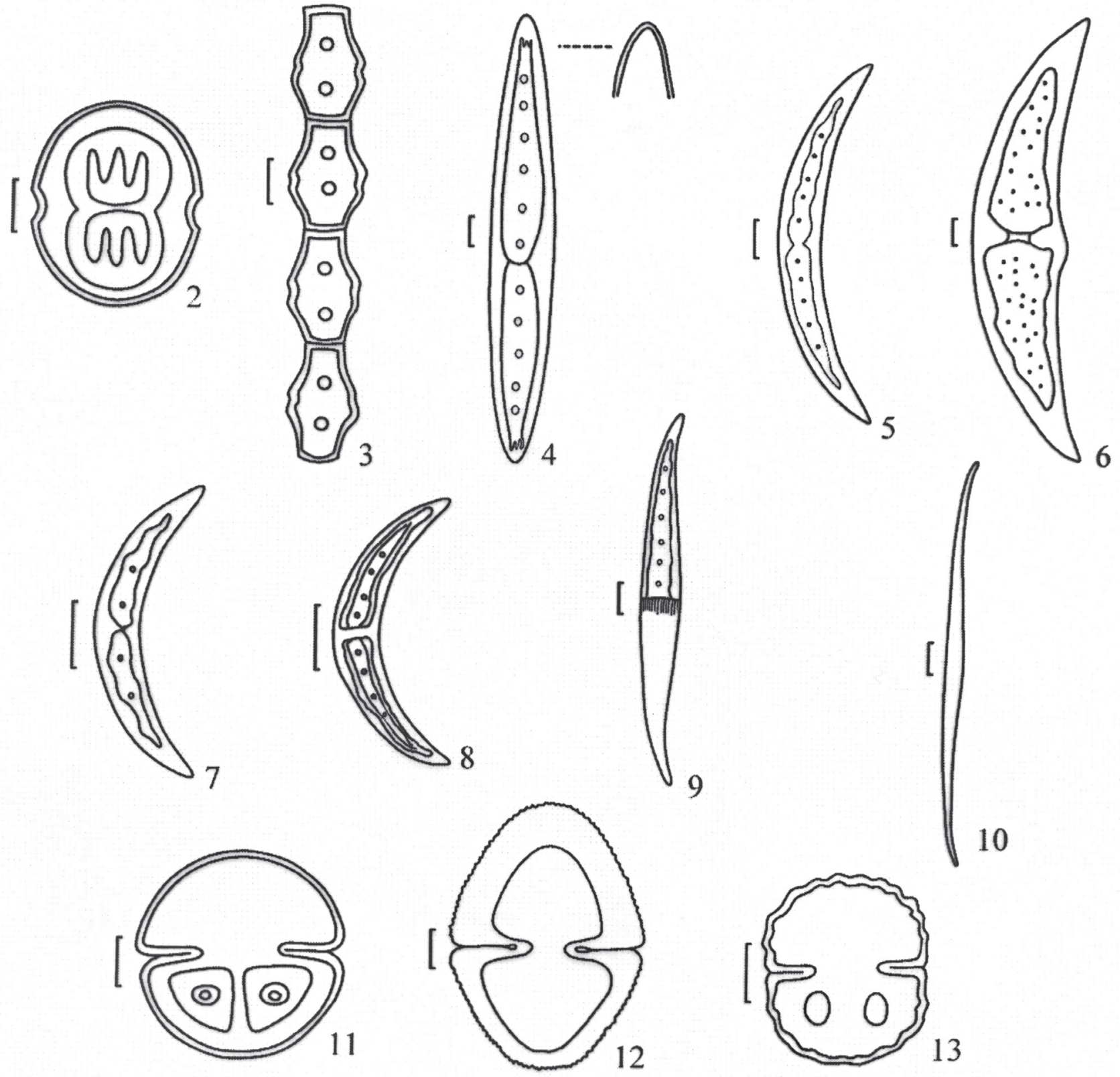

Figuras 2-13. Espécies de desmídias do Rio São João. 2. Actinotaenium globosum. 3. Bambusina brebissonii. 4. Closterium closterioides. 5. Closterium dianae var. minus. 6. Closterium eherenbergii var. immane. 7. Closterium incurvum var. incurvum. 8. Closterium jenneri var. robustum. 9. Closterium ralfsii var. hybridum. 10. Closterium setaceum var. setaceum. 11. Cosmarium candianum var. candianum f. candianum. 12. Cosmarium denticulatum. 13. Cosmarium formosulum var. formosulum. Barras de escala $=10 \mu \mathrm{m}$, exceto figuras 4 , 6 , $8,9,10,12=25 \mu \mathrm{m}$.

Figures 2-13. Species of desmids from the São João River. 2. Actinotaenium globosum. 3. Bambusina brebissonii. 4. Closterium closterioides. 5. Closterium dianae var. minus. 6. Closterium eherenbergii var. immane. 7. Closterium incurvum var. incurvum. 8. Closterium jenneri var. robustum. 9. Closterium ralfsii var. hybridum. 10. Closterium setaceum var. setaceum. 11. Cosmarium candianum var. candianum f. candianum. 12. Cosmarium denticulatum. 13. Cosmarium formosulum var. formosulum. Scale bars $=10 \mu \mathrm{m}$, except figures $4,6,8,9,10,12=25 \mu \mathrm{m}$. 
Material examinado: BRASIL. PARANÁ: Foz do Iguaçu, Parque Nacional do Iguaçu, Rio São João, 17-XIII-2008, J.C. Bortolini 26 (UNOP).

Ocorrência no Paraná: Reservatório de Salto do Vau, Município de União da Vitória (Felisberto \& Rodrigues 2008).

\section{Bambusina Kützing ex Kützing}

Bambusina brebissonii Kützing, Phyc. germ.: 140. 1845.

Figura 3

Célula 1,0-1,2 vezes mais longa que larga, 14,7$21 \mu \mathrm{m}$ compr., 14,7-16,8 $\mu \mathrm{m}$ larg., 12,6 $\mu \mathrm{m}$ istmo, em formato de barrilete, semicélula trapeziforme, margens laterais convexas, retas próximo ao ápice, margem superior truncada, levemente constrita na porção mediana, seno mediano pouco evidente, porém aberto e raso, parede celular lisa, hialina, cloroplasto axial, 1 pirenóide por semicélula.

Material examinado: BRASIL. PARANÁ: Foz do Iguaçu, Parque Nacional do Iguaçu, Rio São João, 25-IX-2008, J.C. Bortolini 2 (UNOP).

Ocorrência no Paraná: Rio Tibagi, nordeste do estado do Paraná (Bittencourt-Oliveira 1993a).

Closterium Nitzsch ex Ralfs

Chave para identificação dos materiais de Closterium estudados

1. Célula semilunada ou lunada

2. Parede celular estriada C. hybridum var. ralfsii

2. Parede celular lisa

3. Pirenóides espalhados pelo cloroplasto C. ehrenbergii var. imane

3. Pirenóides distribuídos em série mediana no cloroplasto

4. Célula fortemente curvada com pólos celulares acuminado-arredondados

C. incurvum var. incurvum

4. Célula fortemente curvada com pólos celulares arredondados C. jenneri var. robustum

1. Célula reta, quase reta ou fusiforme

5. Células com processos setáceos presentes C. setaceum var. setaceum

5. Células sem processos setáceos presentes

6. Célula $6,7-7,8$ vezes mais longa que larga C. closterioides

6. Célula 11 vezes mais longa que larga C. dianae var. minus

Closterium closterioides (Ralfs) Louis \& Peeters, Bull. Jard. Bot. Natl. Belg. 37: 410. $1967 \equiv$ Penium closterioides Ralfs, Brit. Desm.: 152, pl. 34, fig. 4a-b. 1848.

Figura 4

Célula 6,7-7,8 vezes mais longa que larga, 195$230 \mu \mathrm{m}$ compr., 25-34 $\mu \mathrm{m}$ larg., reta ou fusiforme, margens laterais convexas, pólos arredondadotruncados, parede celular lisa, sem espessamento polar, cloroplasto axial, 2-4 cristas, 4-6 pirenóides dispostos em série mediana.

Material examinado: BRASIL. PARANÁ: Foz do Iguaçu, Parque Nacional do Iguaçu, Rio São João, 28-VIII-2008, N.C. Bueno 1078 (UNOP); idem, 28-VIII-2008, N.C. Bueno 1081 (UNOP); idem, 28XI-2008, J.C. Bortolini 18 (UNOP); idem, 30-IV2009, J.C. Bortolini 46 (UNOP); idem, 30-IV-2009, J.C. Bortolini 47 (UNOP); idem, 27-V-2009, J.C. Bortolini 56 (UNOP).
Ocorrência no Paraná: Reservatório de Salto do Vau, Município de União da Vitória (Felisberto \& Rodrigues 2007); Lago Municipal, Município de Cascavel (Bortolini et al. 2009).

Closterium dianae Ehrenberg ex Ralfs var. minus Hieronymus in Engler, Pflanzenw. Öst-Afrikas 1: 1895.

Figura 5

Célula 11 vezes mais longa que larga, 94,3-96,6 $\mu \mathrm{m}$ compr., 6,2-8,2 $\mu \mathrm{m}$ larg., margem dorsal convexa, ventral côncava, pólos obtuso-arredondados, parede celular lisa, cloroplasto axial, 4-6 pirenóides dispostos em série mediana, corpúsculos trepidantes não observados.

Material examinado: BRASIL. Paraná: Foz do Iguaçu, Parque Nacional do Iguaçu, Rio São João, 16-VI-2008, N.C. Bueno 1067 (UNOP).

Ocorrência no Paraná: Reservatório de Salto do 
Vau, Município de União da Vitória (Felisberto \& Rodrigues 2007).

Closterium ehrenbergii Meneghini var. immane Wolle, Bull. Torrey Bot. Club 9(3): 26. 1882. Figura 6

Célula 4,7-5,5 vezes mais longa que larga, 367,5-405,3 $\mu \mathrm{m}$ compr., 69,3-79,8 $\mu \mathrm{m}$ larg., curvada, margem dorsal convexa, margem ventral pouco côncava, inflada na região mediana, pólos arredondados, parede celular lisa, às vezes finamente estriada, cloroplasto axial, vários pirenóides distribuídos pelo cloroplasto, corpúsculos trepidantes presentes.

Material examinado: BRASIL. PARANÁ: Foz do Iguaçu, Parque Nacional do Iguaçu, Rio São João, 28-VIII-2008, N.C. Bueno 1077 (UNOP); idem, 28-VIII-2008, N.C. Bueno 1081 (UNOP); idem, 28VIII-2008, N.C. Bueno 1082 (UNOP); idem, 25-IX2008, J.C. Bortolini 2 (UNOP); idem, 28-X-2008, J.C. Bortolini 12 (UNOP).

Ocorrência no Paraná: Reservatório de Salto do Vau, Município de União da Vitória (Felisberto \& Rodrigues 2007).

Closterium incurvum Brébisson var. incurvum, Mém. Soc. Imp. Sci. Nat. Cherbourg 4: 150, pl. 2, fig. 4. 1856.

Figura 7

Célula 5-6,4 vezes mais longa que larga, 36,974,6 $\mu \mathrm{m}$ compr., 5,7-13,1 $\mu \mathrm{m}$ larg., lunada, fortemente curvada, margem dorsal fortemente convexa, ventral côncava, pólos acuminados a acuminado-arredondados, parede celular incolor e lisa, com espessamento apical, cloroplasto axial, 2-4 pirenóides dispostos em série mediana.

Material examinado: BRASIL. PARANÁ: Foz do Iguaçu, Parque Nacional do Iguaçu, Rio São João, 28-VIII2008, N.C. Bueno 1078 (UNOP); idem, 25-IX-2008, J.C. Bortolini 1 (UNOP); idem, 25-IX-2008, J.C. Bortolini 2 (UNOP).

Ocorrência no Paraná: Rio Tibagi, nordeste do estado (Bittencourt-Oliveira \& Castro 1993); Reservatório de Salto do Vau, Município de União da Vitória (Felisberto \& Rodrigues 2007); Rio São Francisco Falso, Município de Santa Helena (Biolo et al. 2008); Lago Municipal, Município de Cascavel (Bortolini et al. 2009).

Closterium jenneri Ralfs var. robustum G. West, J. Bot. 37: 112, pl. 396, fig. 9. 1899.

Figura 8
Células 7,5 vezes mais longa que larga, 94,5142,8 $\mu \mathrm{m}$ compr., 12,6-18,9 $\mu \mathrm{m}$ larg., lunada, fortemente curvada, margem dorsal fortemente convexa, ventral côncava, não inflada na região mediana, pólos arredondados, parede celular lisa, espessamento polar, cloroplasto axial, presença de cristas, 4-5 pirenóides dispostos em série mediana.

Material examinado: BRASIL. PARANÁ: Foz do Iguaçu, Parque Nacional do Iguaçu, Rio São João, 16-VI-2008, N.C. Bueno 1067 (UNOP); idem, 16VI-2008, N.C. Bueno 1068 (UNOP).

Ocorrência no Paraná: Reservatório de Salto do Vau, Município de União da Vitória (Felisberto \& Rodrigues 2007).

Closterium ralfsii Brébisson ex Ralfs var. hybridum Rabenhorst, Krypt.-Fl. Sachs. 1: 174. 1863. Figura 9

Célula ligeiramente curvada, quase reta, 31 vezes mais longa que larga, 195,3-199,5 $\mu \mathrm{m}$ compr., 6,3-8,4 $\mu \mathrm{m}$ larg., margem dorsal convexa, ventral moderadamente convexa, levemente inflada na região mediana, pólos celulares truncados, parede celular estriada, cloroplasto axial, 10-12 pirenóides dispostos em série mediana.

Material examinado: BRASIL. PARANÁ: Foz do Iguaçu, Parque Nacional do Iguaçu, Rio São João, 22-I-2009, J.C. Bortolini30 (UNOP); idem, 22-I2009, J.C. Bortolini 30 (UNOP); idem, 27-V-2009, J.C. Bortolini 57 (UNOP).

Ocorrência no Paraná: Reservatório de Salto do Vau, Município de União da Vitória (Felisberto \& Rodrigues 2007); Lago Municipal, Município de Cascavel (Bortolini et al. 2009).

Closterium setaceum Ehrenberg ex Ralfs var. setaceum, Brit. Desm. 176, pl. 30, fig. 4. 1848.

Figura 10

Célula fusiforme-lanceolada, 19-21 vezes mais longa que larga, quase reta, 320-346,5 $\mu \mathrm{m}$ compr., 14,7-18 $\mu \mathrm{m}$ larg., margens dorsal e ventral igualmente convexas, sendo a porção mediana fusiforme, pólos truncados, parede celular lisa ou finamente estriada, pouco visível, cloroplasto axial, pirenóides 2-3 em série mediana, processos setáceos longos, corpúsculo trepidante não observado.

Material examinado: BRASIL. PARANÁ: Foz do Iguaçu, Parque Nacional do Iguaçu, Rio São João, 22-I-2009, J.C. Bortolini 30 (UNOP); idem, 27-V2009, J.C. Bortolini 56 (UNOP).

Ocorrência no do Paraná: Parque Regional do 
Iguaçu, Município de Curitiba (Picelli-Vicentim 1984); Rio Tibagi, nordeste do estado (BittencourtOliveira \& Castro 1993); Reservatório de Salto do Vau, Município de União da Vitória (Felisberto \& Rodrigues 2007); Rio do Corvo, Município de
Diamante do Norte (Borges et al. 2008); Lago Municipal, Município de Cascavel (Bortolini et al. 2009).

Cosmarium Corda ex Ralfs

Chave para identificação dos materiais de Cosmarium estudados

1. Parede celular lisa

2. Constrição celular mediana rasa C. pseudoconnatum var. pseudoconnatum

2. Constrição celular mediana profunda

3. Semicélula subtrapeziforme C. trilobulatum var. triloblatum f. trilobulatum

3. Semicélula semicircular

4. Margem apical lisa, com espessamento

C. laeve var. laeve

4. Margem apical lisa, sem espessamento

5. Um pirenóide por semicélula

C. montrealense

5. Dois pirenóides por semicélula C. candianum var. candianum f. candianum

1. Parede celular granulosa

6. Margem lateral denticulada C. denticulatum

6. Margem lateral ondulada

7. Ápice celular com 1 proeminência evidente

7. Ápice celular sem proeminência

8. Parede celular pontuada

C. vexatum

8. Parede celular densamente granulosa

9. Um pirenóide por semicélula

C. punctulatum var. punctulatum

9. Dois pirenóides por semicélula

10. Semicélula de contorno oblongo-elíptico

C. margaritatum var. margaritatum f. margaritatum

10. Semicélula de contorno subsemicircular

C. formosulum var. formosulum

Cosmarium candianum Delponte var. candianum $\mathrm{f}$. candianum, Mém. R. Accad. Sci. Torino 28: 113, pl. 8, fig. 1-6. 1877.

Figura 11

Célula 1-1,1 vezes mais longa que larga, 4145,9 $\mu \mathrm{m}$ compr., 41,8-42,6 $\mu \mathrm{m}$ larg., 12,3-14,7 $\mu \mathrm{m}$ istmo, semicélula subtrapeziforme, margens laterais convexas, lisa, ápice celular e ângulos basais amplamente arredondados, constrição mediana profunda, seno mediano linear, fechado, parede celular finamente pontuada, cloroplasto axial, 2 pirenóides por semicélula, vista lateral subcircular, vista apical elíptica.

Material examinado: BRASIL. PARANÁ: Foz do Iguaçu, Parque Nacional do Iguaçu, Rio São João, 28-VIII-2008, N.C. Bueno 1078 (UNOP); idem, 25-IX-2008, J.C. Bortolini 2 (UNOP); idem, 30IV-2009, J.C. Bortolini 46 (UNOP).

Ocorrência no Paraná: Primeira citação da espécie.
Cosmarium denticulatum Borge, Bih. K. Svenska Vet.-Akad. Handl. 22: 19, pl. 3, fig. 31. 1896. Figura 12

Célula 1,4 vezes mais longa que larga, 165,9$168 \mu \mathrm{m}$ compr., 115,5-117,6 $\mu \mathrm{m}$ larg., 35,7-37,8 $\mu \mathrm{m}$ istmo, semicélula piramidal, margem lateral denticulada, com espinhos, ápice celular truncado, constrição mediana profunda, seno mediano fechado, parede celular com espinhos, cloroplasto e pirenóides de difícil visualização.

Material examinado: BRASIL. PARANÁ: Foz do Iguaçu, Parque Nacional do Iguaçu, Rio São João, 25-IX-2008, J.C. Bortolini 2 (UNOP).

Ocorrência no Paraná: Primeira citação da espécie.

Cosmarium formosulum Hoff in Nordstedt var. formosulum, Vidensk. Medd. Naturh. Foren. Kjöbenhavn: 194, pl. 6, fig. 6-7. 1888.

Figura 13

Célula 1,1 vezes mais longa que larga, 30,7- 
31,5 $\mu \mathrm{m}$ compr., 25,9-26,5 $\mu \mathrm{m}$ larg., 8,9-9,1 $\mu \mathrm{m}$ istmo, semicélula subsemicircular, margens laterais convexas com 5-6 ondulações, ângulos basais arredondados, ápice truncado com 4-5 ondulações, parede celular granulosa em série em direção a região mediana da célula, constrição mediana profunda, seno mediano fechado, quando observadas vista lateral e apical da semicélula, as margens aparecem granuladas e com ângulos basais levemente inflados, cloroplasto com 2 pirenóides por semicélula.

Material examinado: BRASIL. Paraná: Foz do Iguaçu, Parque Nacional do Iguaçu, Rio São João, 25-IX-2008, J.C. Bortolini 1 (UNOP); idem, 27-V2009, J.C. Bortolini 55 (UNOP).

Ocorrência no Paraná: Rio Iguaçu, região da Usina Hidrelétrica de Salto Caxias (Silva \& Cecy 2004).

Cosmarium laeve Rabenhorst var. laeve, Öfv. Kongl. Vet.-Akad. Förhandl. 6: 29, pl. 12, fig. 4. 1876. Figura 14

Célula 1,4 vezes mais longa que larga, 29,1$30,7 \mu \mathrm{m}$ compr., 20,5-21,5 $\mu \mathrm{m}$ larg., $8,2 \mu \mathrm{m}$ istmo, semicélula semicircular, margens laterais convexas e lisas, margem apical lisa e com espessamento, ápice convexo, constrição mediana profunda, seno mediano linear e fechado, parede celular finamente pontuada, cloroplasto axial, 1 pirenóide por semicélula, vista lateral semicircular.

Material examinado: BRASIL. PARANÁ: Foz do Iguaçu, Parque Nacional do Iguaçu, Rio São João, 25-IX-2008, J.C. Bortolini 1 (UNOP).

Ocorrência no Paraná: Rio Iguaçu, região da Usina Hidrelétrica de Salto Caxias (Silva \& Cecy 2004); Reservatório de Iraí, Município de Tijucas do Sul (Cetto et al. 2004).

Cosmarium margaritatum (Lundell) Roy \& Bisset var. margaritatum f. margaritatum, Jour. Bot. 24: 194. 1885.

Figura 15

Célula 1,2-1,3 vezes mais longa que larga, 46,7-53,5 $\mu \mathrm{m}$ compr., 36,9-41,8 $\mu \mathrm{m}$ larg., 10,6-13,4 $\mu \mathrm{m}$ istmo, semicélula oblonga-elíptica, contorno subquadrático, constrição mediana profunda, seno mediano linear dilatado na sua extremidade, margens apical e lateral ondulada, ângulos basais e apicais arredondados, parede celular granulosa, vista lateral da semicélula subcircular, vista apical oblonga, cloroplasto axial, 2 pirenóides por semicélula.

Material examinado: BRASIL. PARANÁ: Foz do Iguaçu, Parque Nacional do Iguaçu, Rio São João,
16-VI-2008, N.C. Bueno 1067 (UNOP); idem, 25IX-2008, J.C. Bortolini 1 (UNOP).

Ocorrência no Paraná: Curitiba e arredores (Lozovei \& Luz 1976); Município de Curitiba (Lozovei \& Hohmann 1977); Represa do Rio Passaúna, Município de Araucária (Cecy et al. 1997); Reservatório de Iraí, Município de Tijucas do Sul (Cetto et al. 2004).

Cosmarium montrealense Croasdale in Prescott et al., Syn. N.A. Desmids, 2(3): 195, pl. 171, fig. 14. 1981.

Figura 16

Célula 1,1 vezes mais longa que larga, 34,435,6 $\mu \mathrm{m}$ compr., 31,1-36,4 $\mu \mathrm{m}$ larg., 9,7-9,8 $\mu \mathrm{m}$ istmo, semicélula subsemicircular, margens laterais e apicais lisas, parede celular lisa, cloroplasto axial, 1 pirenóide por semicélula, vista lateral subcircular, vista apical elíptica.

Material examinado: BRASIL. PARANÁ: Foz do Iguaçu, Parque Nacional do Iguaçu, Rio São João, 16-IV-2008, N.C. Bueno 1068 (UNOP).

Ocorrência no Paraná: Primeira citação da espécie.

Cosmarium protractum (Nägeli) De Bary var. protractum, Conjug.: $72.1858 \equiv$ Euastrum protractum Nägeli, Gatt. Einz. Algen.: 119, pl. 7, fig. 4. 1849.

\section{Figura 17}

Célula 1,0 vezes mais longa que larga, ou tão longa quanto larga, 21,8-26,7 $\mu \mathrm{m}$ compr., 29,9-20,2 $\mu \mathrm{m}$ larg., 6,4-8,1 $\mu \mathrm{m}$ istmo, semicélula subcircular a subretangular, 3-lobada, ápice proeminentemente truncado, margens laterais arredondadas, constrição mediana profunda, seno mediano aberto próximo ao istmo e mais fechado na região distal, parede celular granulosa, cloroplasto com 2 pirenóides por semicélula, vista apical oblonga a elíptica.

Material examinado: BRASIL. PARANÁ: Foz do Iguaçu, Parque Nacional do Iguaçu, Rio São João, 28-VIII-2008, N.C. Bueno 1078 (UNOP); idem, 25IX-2008, J.C. Bortolini 2 (UNOP).

Ocorrência no Paraná: Represa do Rio Passaúna, Município de Araucária (Cecy et al. 1997).

Cosmarium pseudoconnatum Nordstedt var. pseudoconnatum, Vidensk. Medd. Naturh. Foren. Kjöbenhavn, 21: 214, pl. 3, fig. 17. 1870 $\equiv$ Calocylindrus pseudoconnatus Nordstedt in Wolle, Bull. Torr. Club 8(11): 39. 1881.

Figura 18

Célula 1,2-1,3 vezes mais longa que larga, 

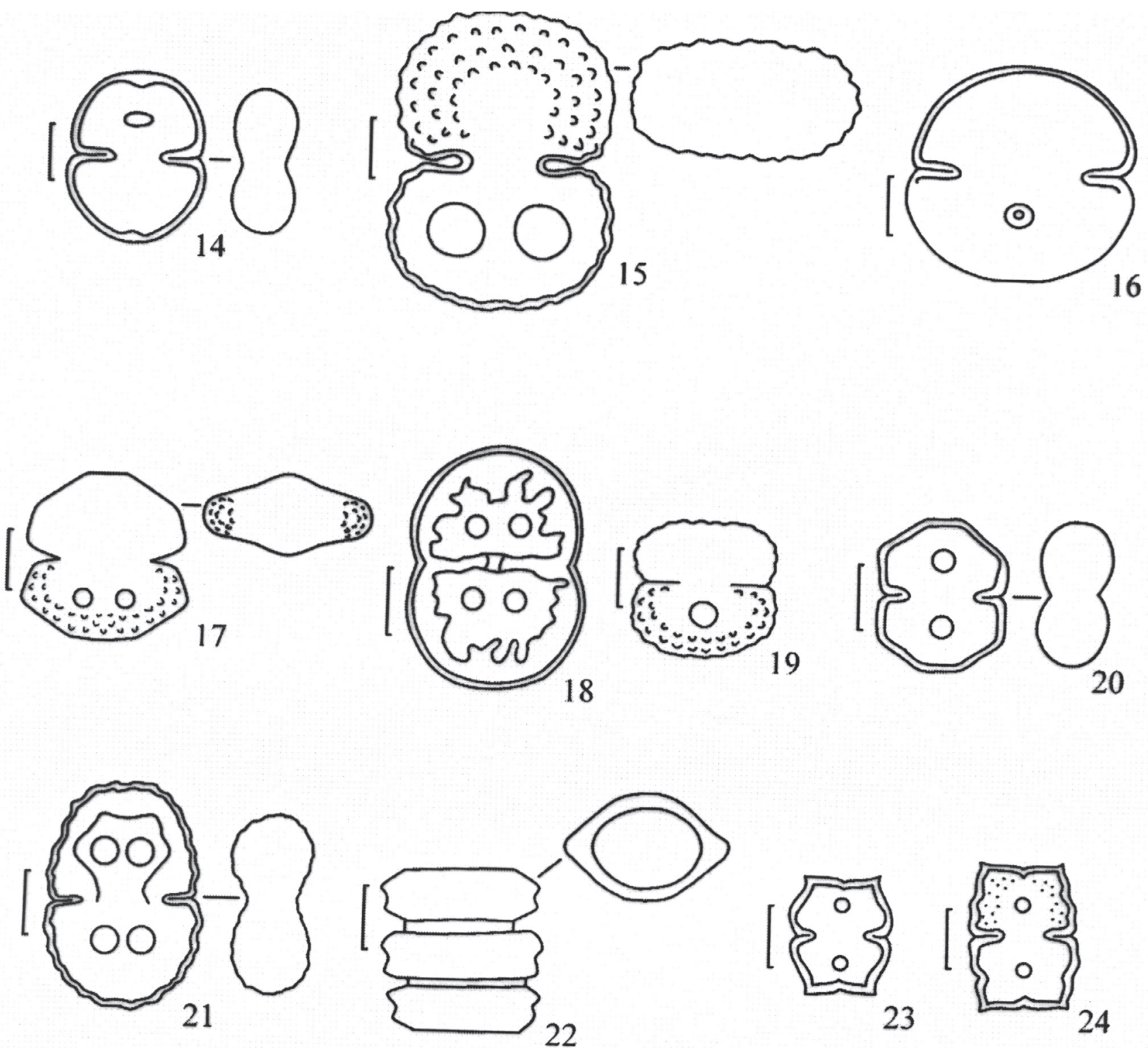

23

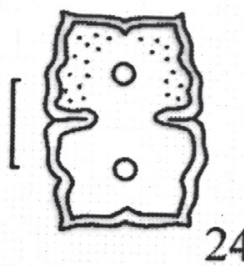

Figuras 14-24. Espécies de desmídias do Rio São João. 14. Cosmarium laeve var. laeve. 15. Cosmarium margaritatum var. margaritatum f. margaritatum 16. Cosmarium montrealense. 17. Cosmarium protractum var. protractum. 18. Cosmarium pseudoconnatum var. pseudoconnatum. 19. Cosmarium punctulatum var. punctulatum. 20. Cosmarium trilobulatum var. trilobulatum f. trilobulatum. 21. Cosmarium vexatum. 22. Desmidium cylindricum. 23. Euastrum insulare. 24. Euastrum denticulatum. Barras de escala $=10 \mu \mathrm{m}$, exceto figura $22=25 \mu \mathrm{m}$.

Figures 14-24. Species of desmids from the São João River. 14. Cosmarium laeve var. laeve. 15. Cosmarium margaritatum var. margaritatum f. margaritatum. 16. Cosmarium montrealense. 17. Cosmarium protractum var. protractum. 18. Cosmarium pseudoconnatum var. pseudoconnatum. 19. Cosmarium punctulatum var. punctulatum. 20. Cosmarium trilobulatum var. trilobulatum f. trilobulatum. 21. Cosmarium vexatum. 22. Desmidium cylindricum. 23. Euastrum insulare. 24. Euastrum denticulatum. Scale bars $=10 \mu \mathrm{m}$, except figure $22=25 \mu \mathrm{m}$. 
36,9-53,3 $\mu \mathrm{m}$ compr., 28,7-41,8 $\mu \mathrm{m}$ larg., 24,6$39,3 \mu \mathrm{m}$ istmo, contorno ovalado-arredondado, semicélula semicircular, constrição mediana rasa, seno mediano aberto, margens apical e laterais lisas, ápice arredondado, parede celular finamente pontuada, cloroplasto axial, radiado, 2 pirenóides por semicélula, vista apical da célula circular.

Material examinado: BRASIL. PARANÁ: Foz do Iguaçu, Parque Nacional do Iguaçu, Rio São João, 16-VI-2008, N.C. Bueno 1068 (UNOP); idem, 28VIII-2008, N.C. Bueno 1077 (UNOP); idem, 28VIII-2008, N.C. Bueno 1078 (UNOP); idem, 25-IX2008, J.C. Bortolini 2 (UNOP); idem, 26-III-2009, J.C. Bortolini 41 (UNOP); idem, 27-V-2009, J.C. Bortolini 57 (UNOP).

Ocorrência no Paraná: Parque Regional do Iguaçu, Município de Curitiba (Picelli-Vicentim 1984); Rio Tibagi, nordeste do estado (Bittencourt-Oliveira 1993b); Represa do Rio Passaúna, Município de Araucária (Cecy et al. 1997); Represa do Rio Passaúna (Picelli-Vicentim et al. 2001); Rio Iguaçu, região da Usina Hidrelétrica de Salto Caxias (Silva \& Cecy 2004); Reservatório de Salto do Vau, Município de União da Vitória (Felisberto \& Rodrigues 2008).

\section{Cosmarium punctulatum Brébisson var.} punctulatum, Mém. Soc. Imp. Sci. Nat. Cherbourg 4: 129, pl. 1, fig. 16. 1856.

Figura 19

Célula 1,1 vezes mais longa que larga, 22,9-26,7 $\mu \mathrm{m}$ compr., 20,5-26,7 $\mu \mathrm{m}$ larg., 5,7-6,1 $\mu \mathrm{m}$ istmo, semicélula com formato oblongo a trapeziforme, margens laterais onduladas, constrição mediana profunda, seno mediano fechado, parede celular acentuadamente granulosa, cloroplasto axial, 1 pirenóide, vista apical elíptica, vista lateral subcircular.

Material examinado: BRASIL. PARANÁ: Foz do Iguaçu, Parque Nacional do Iguaçu, Rio São João, 16-VI-2008, N.C. Bueno 1068 (UNOP).

Ocorrência no Paraná: Curitiba e arredores (Lozovei \& Luz 1976); Município de Curitiba (Lozovei \& Hohmann 1977); Represa do Rio Passaúna, Município de Araucária (Cecy et al. 1997); Rio Iguaçu, região da Usina Hidrelétrica de Salto Caxias (Silva \& Cecy 2004); Reservatório de Iraí, Município de Tijucas do Sul, (Cetto et al. 2004); Reservatório de Salto do Vau, Município de União da Vitória (Felisberto \& Rodrigues 2008).

\section{Cosmarium trilobulatum Reinsch var. trilobulatum}

f. trilobulatum, Acta Soc. Senckenb. 6: 118, pl. 22A2, fig. 1-6. 1867.

Figura 20

Célula 1,1-1,2 vezes mais longa que larga, 23,7-26,2 $\mu \mathrm{m}$ compr., 20,5-22,1 $\mu \mathrm{m}$ larg., 4,1-6,5 $\mu \mathrm{m}$ istmo, célula subtrapeziforme, parede celular finamente pontuada, cloroplasto axial, 1 pirenóide por semicélula, vista lateral subcircular e vista apical da célula elíptica.

Material examinado: BRASIL. PARANÁ: Foz do Iguaçu, Parque Nacional do Iguaçu, Rio São João, 16-VI-2008, N.C. Bueno 1067 (UNOP); idem, 28VIII-2008, N.C. Bueno 1077 (UNOP); idem, 28VIII-2008, N.C. Bueno 1078 (UNOP); idem, 25-IX2008, J.C. Bortolini 1 (UNOP); idem, 25-IX-2008, J.C. Bortolini 2 (UNOP); idem, 25-IX-2008, J.C. Bortolini 3 (UNOP); idem, 28-X-2008, J.C. Bortolini 11 (UNOP).

Ocorrência no Paraná: Rio Cachoeira, Município de Antonina (Stankiewicz 1980); Parque Regional do Iguaçu, Município de Curitiba (Picelli-Vicentim 1984); Rio Tibagi, nordeste do estado (BittencourtOliveira 1993b).

Cosmarium vexatum West, J. Roy. Micr. Soc.: 727, pl. 9, fig. 33. 1892.

Figura 21

Célula 1,3 vezes mais longa que larga, 21-35 $\mu \mathrm{m}$ compr., 16,8-26,2 $\mu \mathrm{m}$ larg., 8,4-11,4 $\mu \mathrm{m}$ istmo, semicélula piramidal, margens onduladas, ápice truncado, constrição mediana profunda, seno mediano fechado, parede celular pontuada, cloroplasto axial, 2 pirenóides por semicélula, vista lateral semicircular, vista apical oval.

Material examinado: BRASIL. PARANÁ: Foz do Iguaçu, Parque Nacional do Iguaçu, Rio São João, 25-IX-2008, J.C. Bortolini 2 (UNOP); idem, 28-XI2008, J.C. Bortolini 17 (UNOP).

Ocorrência no Paraná: Reservatório de Salto do Vau, Município de União da Vitória (Felisberto \& Rodrigues 2008).

Desmidium C. Agardh ex Ralfs

Desmidium cylindricum Greville, Scot. Crypt. F1.: 5, pl. 293. 1827.

Figura 22

Célula 2,4-2,8 vezes mais larga que longa, 2131,5 $\mu \mathrm{m}$ compr., 58,8-75, $6 \mu \mathrm{m}$ larg., 50,4-65,1 $\mu \mathrm{m}$ istmo, semicélulas piramidado-truncadas, constrição mediana moderada, seno mediano aberto, linear, 
margens laterais com uma pequena intumescência basal acutangular-arredondada, ondulada próximo ao seno mediano, margem superior truncada, parede celular lisa, cloroplasto axial, 6-8-lobados, 1 pirenóide por semicélula, vista apical elíptica com 1 pequena protuberância em cada pólo.

Material examinado: BRASIL. PARANÁ: Foz do Iguaçu, Parque Nacional do Iguaçu, Rio São João, 28-VIII-2008, N.C. Bueno 1077 (UNOP); idem, 28-VIII-2008, N.C. Bueno 1078 (UNOP); idem, 28VIII-2008, N.C. Bueno 1079 (UNOP); idem, 25-IX2008, J.C. Bortolini 1 (UNOP); idem, 25-IX-2008, J.C. Bortolini 2 (UNOP); idem, 25-IX-2008, J.C. Bortolini 3 (UNOP); idem, 28-X-2008, J.C. Bortolini 11 (UNOP); idem, 17-XII-2008, J.C. Bortolini 25(UNOP); idem, 26-III-2009, J.C. Bortolini 40 (UNOP); idem, 26-III-2009,J.C. Bortolini41(UNOP); idem, 26-III-2009, J.C. Bortolini 42 (UNOP); idem, 30-IV-2009, J.C. Bortolini 46 (UNOP); idem, 30-IV2009, J.C. Bortolini 47 (UNOP); idem, 27-V-2009, J.C. Bortolini 56 (UNOP); idem, 27-V-2009, J.C. Bortolini 57 (UNOP).

Ocorrência no Paraná: Primeira citação da espécie.

\section{Euastrum Ehrenberg ex Ralfs}

Chave para identificação dos materiais de Euastrum estudados

1. Semicélula subtrapeziforme sem espinho nos ângulos apicais E. insulare

1. Semicélula subtrapeziforme com pequeno espinho nos ângulos apicais E. denticulatum

Euastrum insulare (Wittrock) Roy, Monogr. Scott. Nat. 1877: 68. 1877 E Euastrum binale (Turp.) Ehrenberg ex Ralfs var. insulare Wittrock, Bih. Kongl. Vet.-Akad. Handl. 1: 49. 1872.

Figura 23

Célula 1,1 vezes mais longa que larga, 17,218,6 $\mu \mathrm{m}$ compr., 16,4-17,8 $\mu \mathrm{m}$ larg., 6,5-7,2 $\mu \mathrm{m}$ istmo, semicélula subtrapeziforme, margens laterais levemente onduladas, incisão apical mediana rasa, seno mediano fechado, cloroplasto axial, 1 pirenóide por semicélula.

Material examinado: BRASIL. PARANÁ: Foz do Iguaçu, Parque Nacional do Iguaçu, Rio São João, 16-VI-2008, N.C. Bueno 1067 (UNOP); idem, 27-II2009, J.C. Bortolini 34 (UNOP).

Ocorrência no Paraná: Represa do Rio Passaúna (Picelli-Vicentim et al. 2001); Rio São Francisco
Falso, Município de Santa Helena (Biolo et al. 2008).

Euastrum denticulatum Gay, Bull. Soc. Bot. Fr. 31: 335.1884.

Figura 24

Célula 1,2 vezes mais longa que larga, 21,322,6 $\mu \mathrm{m}$ compr., 18-18,6 $\mu \mathrm{m}$ larg., 7,3-8,1 $\mu \mathrm{m}$ istmo, semicélula subtrapeziforme, margens laterais onduladas, lobos basais retangulares, incisão apical mediana profunda, pequeno espinho nos ângulos apicais, constrição mediana profunda, seno fechado, parede celular granulosa, cloroplasto axial, 1 pirenóide por semicélula.

Material examinado: BRASIL. PARANÁ: Foz do Iguaçu, Parque Nacional do Iguaçu, Rio São João, 16-VI-2008, N.C. Bueno 1068 (UNOP); idem, 27-V2009, J.C. Bortolini 57 (UNOP).

Ocorrência no Paraná: Reservatório de Salto do Vau, Município de União da Vitória (Felisberto \& Rodrigues 2008).

\section{Gonatozygon De Bary}

Chave para identificação dos materiais de Gonatozygon estudados

1. Parede celular coberta por espinhos G. pilosum

1. Parede celular sem espinhos

2. Pólo celular levemente arredondado G. monotaenium

2. Pólo celular truncado e levemente dilatado G. kinahanii

Gonatozygon kinahanii (Archer) Rabenhorst, Fl. Eur. Alg. 3: 156. 1868.

Figura 25

Célula 6,2-14 vezes mais longa que larga, 52,5235,2 $\mu \mathrm{m}$ compr., 8,4-16, $8 \mu \mathrm{m}$ larg., cilíndricas, pólo celular truncado e levemente dilatado, margens laterais retilíneas e lisas, parede celular lisa, cloroplasto axial, 8-12 pirenóides dispostos em série longitudinal ao longo do cloroplasto.

Material examinado: BRASIL. PARANÁ: Foz do Iguaçu, Parque Nacional do Iguaçu, Rio São João, 28-VIII-2008, N.C. Bueno 1077 (UNOP); idem, 28-VIII-2008, N.C. Bueno 1078 (UNOP); idem, 28-VIII-2008, N.C. Bueno 1079 (UNOP); idem, 28VIII-2008, N.C. Bueno1080 (UNOP); idem, 25-IX2008, J.C. Bortolini 1 (UNOP); idem, 25-IX-2008, J.C. Bortolini 2 (UNOP); idem, 25-IX-2008, J.C. 

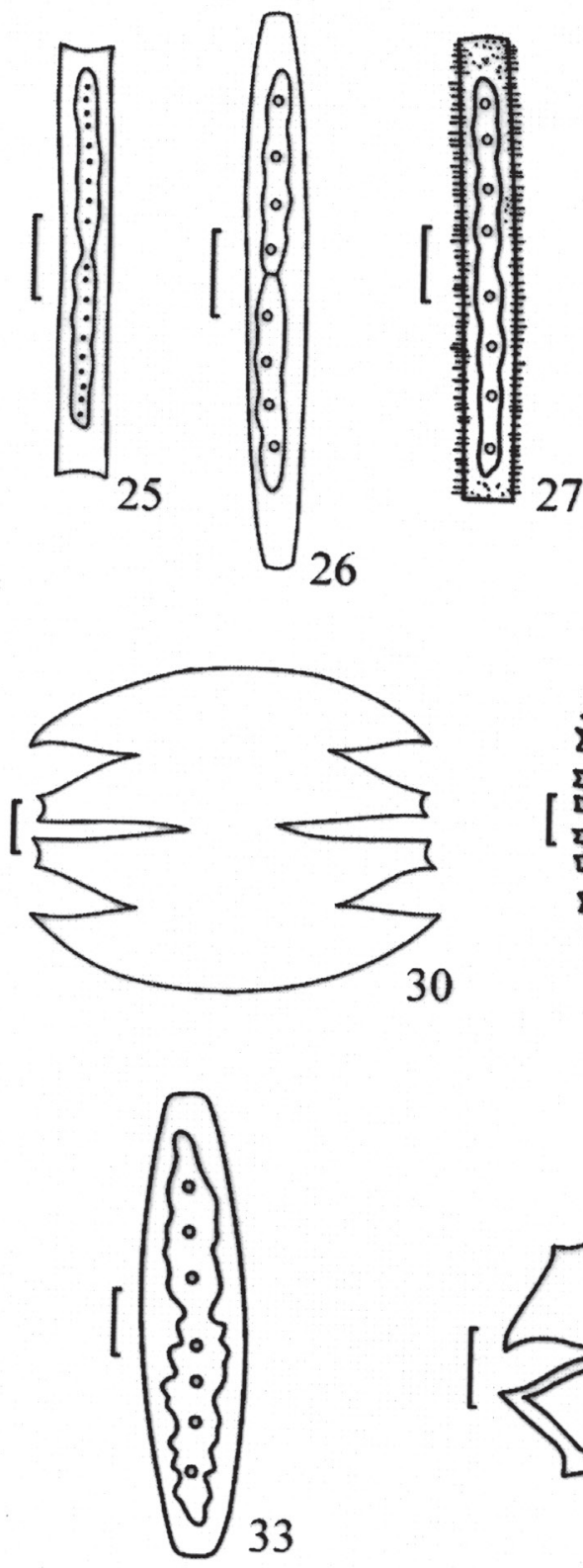
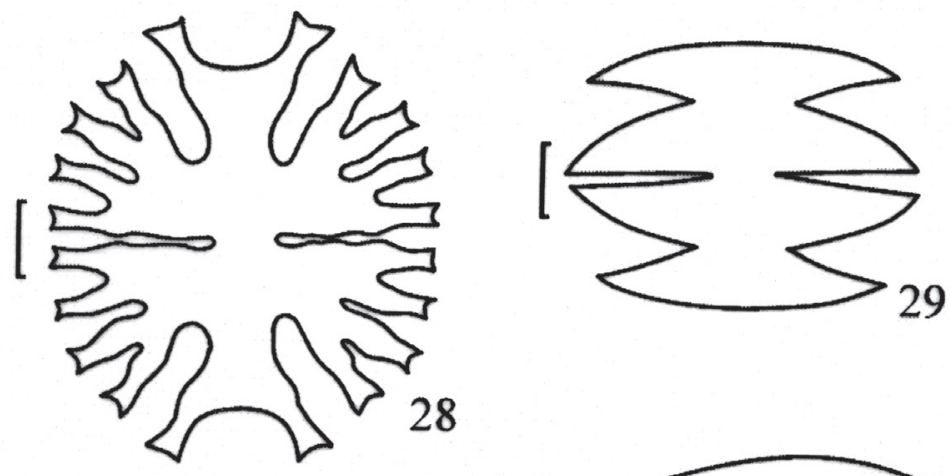

27
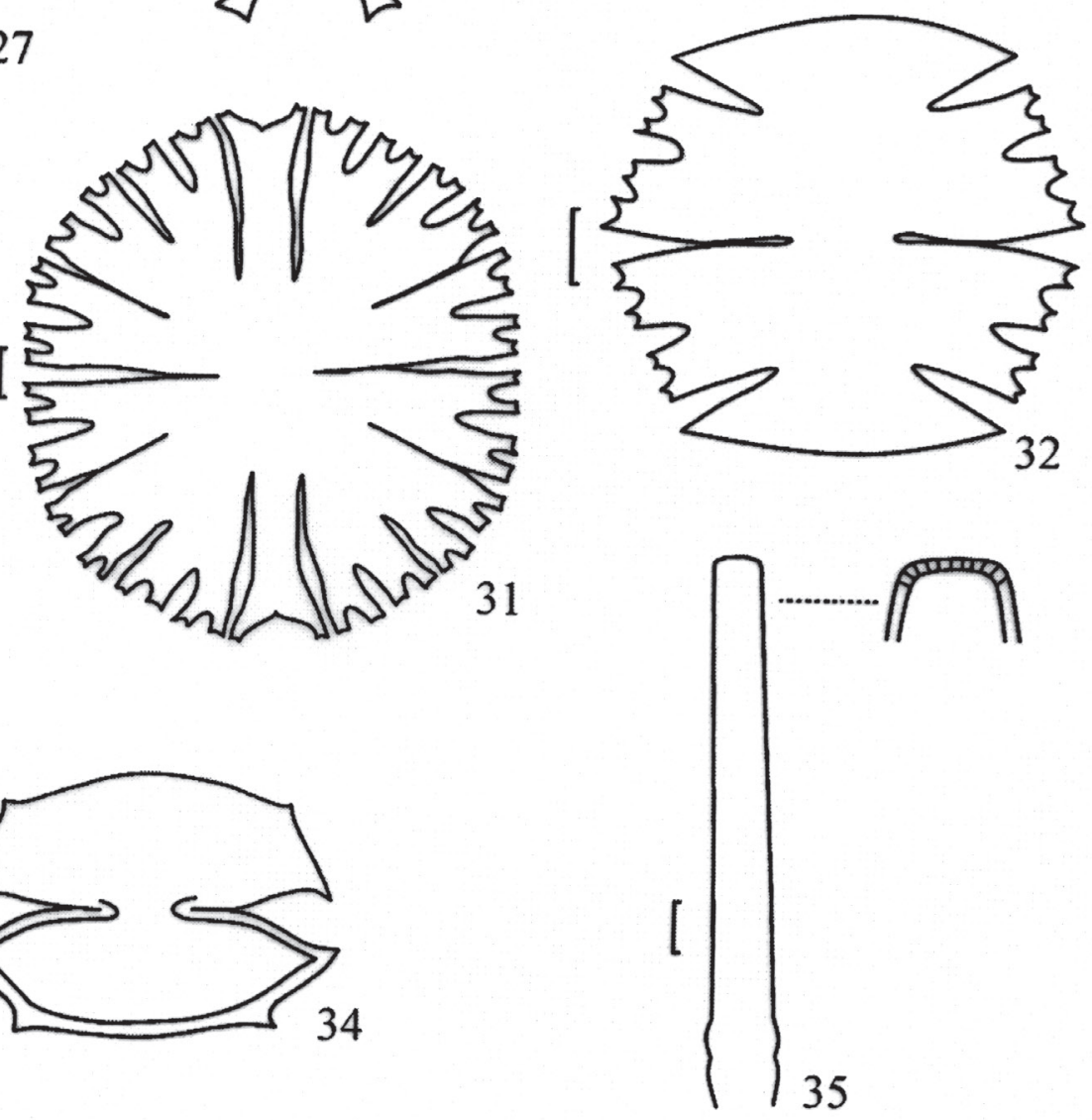

Figuras 25-35. Espécies de desmídias do Rio São João. 25. Gonatozygon kinahanii. 26. Gonatozygon monotaenium. 27. Gonatozygon pilosum. 28. Micrasterias furcata var. furcata. 29. Micrasterias laticeps var. acuminata. 30. Micrasterias laticeps var. laticeps. 31. Micrasterias rotata var. rotata. 32. Micrasterias truncata var. pusilla. 33. Netrium digitus. 34. Octacanthium mucronulatum var. mucronulatum. 35. Pleurotaenium ehrenbergii var. ehrenbergii. Barras de escala $=25 \mu \mathrm{m}$, exceto figuras $31,32,34=10 \mu \mathrm{m}$.

Figures 25-35. Species of desmids from the São João River. 25. Gonatozygon kinahanii. 26. Gonatozygon monotaenium. 27. Gonatozygon pilosum. 28. Micrasterias furcata var. furcata. 29. Micrasterias laticeps var. acuminata. 30. Micrasterias laticeps var. laticeps. 31. Micrasterias rotata var. rotata. 32. Micrasterias truncata var. pusilla. 33. Netrium digitus. 34. Octacanthium mucronulatum var. mucronulatum. 35. Pleurotaenium ehrenbergii var. ehrenbergii. Scales bars $=25 \mu \mathrm{m}$, except figures $31,32,34=10 \mu \mathrm{m}$. 
Bortolini 3 (UNOP); idem, 28-X-2008, J.C. Bortolini 11 (UNOP); idem, 28-X-2008, J.C. Bortolini 12 (UNOP); idem, 28-XI-2008, J.C. Bortolini 16 (UNOP); idem, 28-XI-2008, J.C. Bortolini 17 (UNOP); idem, 28-XI-2008, J.C. Bortolini 18 (UNOP); idem, 22-I-2009, J.C. Bortolini 28 (UNOP); idem, 27-V-2009, J.C. Bortolini 55 (UNOP).

Ocorrência no Paraná: Primeira citação da espécie.

Gonatozygon monotaenium De Bary, Hedwigia 1: 106. 1856.

Figura 26

Célula 11,2-23,7 vezes mais longa que larga, 162,7-182,7 $\mu \mathrm{m}$ compr., 14,4-16,4 $\mu \mathrm{m}$ larg., cilíndricas, pólo celular levemente arredondado, margem lateral retas, lisas, parede celular lisa, cloroplasto axial, 4-5 pirenóides dispostos longitudinalmente.

Material examinado: BRASIL. PARANÁ: Foz do Iguaçu, Parque Nacional do Iguaçu, Rio São João, 28-VIII-2008, N.C. Bueno 1077 (UNOP); idem, 25IX-2008, J.C. Bortolini 1 (UNOP); idem, 25-IX2008, J.C. Bortolini 2 (UNOP); idem, 22-I-2009, J.C. Bortolini 28 (UNOP).

Ocorrência no Paraná: Rio Tibagi, nordeste do estado (Bittencourt-Oliveira 1993a); Reservatório de Salto do Vau, Município de União da Vitória (Felisberto \& Rodrigues 2008).

Gonatozygon pilosum Wolle, Bull. Torrey Bot. Club 9(3): 27, pl. 13, fig. 16. 1882.

Figura 27

Célula 10 vezes mais longa que larga, 138,6$147 \mu \mathrm{m}$ compr., 12,6-14,7 $\mu \mathrm{m}$ larg., 2,1-4,2 $\mu \mathrm{m}$ esp., cilíndrica, pólo celular levemente arredondado, margens laterais retas e cobertas por pequenos espinhos, parede celular pontuada, cloroplastídio laminar, axial, 1 por semicélula, 4-6 pirenóides.

Material examinado: BRASIL. PARANÁ: Foz do Iguaçu, Parque Nacional do Iguaçu, Rio São João, 16-VI-2008, N.C. Bueno 1067 (UNOP); idem, 22-I-2009, J.C. Bortolini 28 (UNOP); idem, 22-I2009, J.C. Bortolini 30 (UNOP); idem, 26-III-2009, J.C. Bortolini 40 (UNOP); idem, 27-V-2009, J.C. Bortolini 56 (UNOP).

Ocorrência no Paraná: Parque Regional do Iguaçu, Município de Curitiba (Picelli-Vicentin 1984); Lago do Parque Barigui, Município de Curitiba (Cecy 1986); Rio Tibagi, nordeste do estado (BittencourtOliveira 1993a); Represa do Rio Passaúna (PicelliVicentim et al. 2001).
Micrasterias C. Agardh ex Ralfs

Chave para identificação dos materiais de Micrasterias estudados

1. Semicélula 3-lobada

2. Lobos basais 2-denticulados M. laticeps var. laticeps

2. Lobos basais acuminados M. laticeps var. acuminata

1. Semicélula 5-lobada

3. Incisões interlobulares pouco abertas M. truncata var. pusilla

3. Incisões interlobulares semiabertas ou abertas

4. Lobos basais e laterais divididos em 2 lóbulos 2-denticulados

M. furcata var. furcata

4. Lobos laterais divididos em 8 lóbulos, 2-denticulados, lobos basais divididos em 4 lóbulos, 2-denticulados

M. rotata var. rotata

Micrasterias furcata C. Agardh ex Ralfs var. furcata, Brit. Desm.: 73, pl. 9, fig. 2. 1848.

Figura 28

Célula 1,1 vezes mais longa que larga,

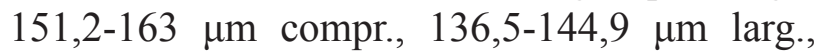
18,9-21 $\mu \mathrm{m}$ istmo, semicélula semicircular, 5-lobada, constrição mediana profunda, seno mediano fechado próximo ao istmo, incisões interlobulares profundas e abertas, lobos laterais e basais divididos em 2 lóbulos 2-denticulados, lobo apical subcilíndrico, margens retas e paralelas, margem superior côncava, ângulos formando processos divergentes, parede celular finamente pontuada, cloroplasto seguindo a forma celular.

Material examinado: BRASIL. PARANá: Foz do Iguaçu, Parque Nacional do Iguaçu, Rio São João, 16-IV-2008, N.C. Bueno 1066 (UNOP); idem, 30-IV2009, J.C. Bortolini 47 (UNOP).

Ocorrência no Paraná: Represa do Rio Passaúna, Município de Araucária (Cecy et al. 1997); Rio São Francisco Falso, Município de Santa Helena (Biolo et al. 2008).

Micrasterias laticeps Nordstedt var. acuminata Krieger in Rabenhorst, Krypt.-Fl. Deutschl. 13(2): 14, pl. 98, fig. 2. 1939.

Figura 29 
Célula 1,2-1,3 vezes mais larga que longa, 88,296,6 $\mu \mathrm{m}$ compr., 115,5-123,9 $\mu \mathrm{m}$ larg., $21 \mu \mathrm{m}$ istmo, 3-lobada, lobos basais e laterais acuminados, lobo apical ligeiramente convexo, separado dos lobos laterais por duas incisões profundas, margens lisas, constrição mediana profunda, seno mediano linear e aberto, parede celular lisa, cloroplasto seguindo o contorno da célula, pirenóides não observados.

Material examinado: BRASIL. PARANÁ: Foz do Iguaçu, Parque Nacional do Iguaçu, Rio São João, 17-XII-2008, J.C. Bortolini 25 (UNOP).

Ocorrência no Paraná: Rio Cachoeira, Município de Antonina (Stankiewicz 1980); Rio Tibagi, nordeste do estado (Bittencourt-Oliveira \& Mecenas 1994); Rio Passaúna, Município de Araucária (Cecy et al. 1997); Rio Tibagi, Município de Sertanópolis (Bittencourt-Oliveira 2002).

\section{Micrasterias laticeps Nordstedt var. laticeps,}

Vidensk. Medd. Naturh. Foren Kjöbenhavn 21: 220, pl. 2, fig. 14. 1870.

Figura 30

Célula 1,2 vezes mais larga que longa, 157,5$168 \mu \mathrm{m}$ compr., 199,5-210 $\mu \mathrm{m}$ larg., 21-25,2 $\mu \mathrm{m}$ istmo, semicélula semicircular, 3-lobada, incisões interlobulares profundas, acutangulares, lobos basais 2-denticulados, lobo apical fusiforme com margem apical convexa na porção mediana, ângulos acuminados, constrição mediana profunda, seno mediano fechado, parede celular finamente pontuada. Material examinado: BRASIL. PARANÁ: Foz do Iguaçu, Parque Nacional do Iguaçu, Rio São João, 25-IX-2008, J.C. Bortolini 2 (UNOP).

Ocorrência no Paraná: Marques dos Reis, Município de Jacarezinho (Andrade \& Rachou 1954); Município de Curitiba (Lozovei \& Hohmann 1977); Parque Regional do Iguaçu, Município de Curitiba (PicelliVicentim 1984); Rio Tibagi, nordeste do estado (Bittencourt-Oliveira \& Mecenas 1994); Rio Tibagi, Município de Sertanópolis (Bittencourt-Oliveira 2002); Reservatório de Salto do Vau (Felisberto \& Rodrigues 2008); Rio São Francisco Falso, Município de Santa Helena (Biolo et al. 2008).

Micrasterias rotata (Greville) Ralfs ex Ralfs var. rotata, Ann. Mag. Nat. Hist. 14: 259. $1844 \equiv$ Echinella rotata Greville in Hooker, Brit. Flora 2: 398. 1833.

Figura 31

Célula 1,1-1,2 vezes mais longa que larga, 279,3$294 \mu \mathrm{m}$ compr., 243,6-249,9 $\mu \mathrm{m}$ larg., 14-15 $\mu \mathrm{m}$ istmo, semicélula semicircular, 5-lobada, lobos basais e laterais divididos em 8 lóbulos, 2-denticulados, lobos basais divididos em 4 lóbulos, 2-denticulados, lobo apical subcilíndrico, margens retas, ápice chanfrado, ângulos projetados, 2-denticulados, constrição mediana profunda, seno mediano linear, incisões interlobulares profundas e lineares, semiabertas, parede celular lisa, cloroplasto seguindo o contorno celular.

Material examinado: BRASIL. PARANÁ: Foz do Iguaçu, Parque Nacional do Iguaçu, Rio São João, 28-VIII-2008, N.C. Bueno 1077 (UNOP); idem, 28VIII-2008, N.C. Bueno 1078 (UNOP); idem, 26-III2009, J.C. Bortolini 40 (UNOP).

Ocorrência no Paraná: Curitiba e arredores, Município de Curitiba (Lozovei \& Luz 1976); Município de Curitiba (Lozovei \& Hohmann 1977); Rio Cachoeira, Município de Antonina (Stankiewicz 1980); Rio Tibagi, nordeste do estado (BittencourtOliveira \& Mecenas 1994); Rio Tibagi, Município de Sertanópolis (Bittencourt-Oliveira 2002); Reservatório de Salto do Vau, Município de União da Vitória (Felisberto \& Rodrigues 2008); Rio São Francisco Falso, Município de Santa Helena (Biolo et al. 2008).

Micrasterias truncata (Corda) Brébisson ex Ralfs var. pusilla G. West, Mém. Soc. Neuchât. Sci. Nat. 5: 1035, pl. 22, fig. 42-43. 1914.

Figura 32

Célula 1,1-1,2 vezes mais larga que longa, 5962,3 $\mu \mathrm{m}$ compr., 63,9-70,5 $\mu \mathrm{m}$ larg., 12,3-15,5 $\mu \mathrm{m}$ istmo, semicélula semicircular, 5-lobada, incisões interlobulares pouco abertas, lobos laterais e basais divididos em 2 lóbulos, 2-denticulados, incisão entre os lóbulos pouco profunda e aberta, lobo apical subfusiforme com ápice truncado, levemente convexo, ângulos acuminados, constrição mediana profunda, seno linear mediano fechado, parede celular lisa, cloroplasto axial.

Material examinado: BRASIL. PARANÁ: Foz do Iguaçu, Parque Nacional do Iguaçu, Rio São João, 28-VIII-2008, N.C. Bueno 1078 (UNOP); idem, 25IX-2008, J.C. Bortolini 1 (UNOP).

Ocorrência no Paraná: Represa do Rio Passaúna, Município de Araucária (Cecy et al. 1997); Represa do Rio Passaúna (Picelli-Vicentim et al. 2001); Reservatório de Salto do Vau, Município de União da Vitória (Felisberto \& Rodrigues 2008); Rio São Francisco Falso, Município de Santa Helena (Biolo et al. 2008). 
Netrium (Nägeli) Itzigsohn \& Rothe emend. Lütkemüller

Netrium digitus (Ehrenberg) Itzighson \& Rothe, Rabenhorst, Alg. Sachs. Dec. 51/52: 508. 1856.

Figura 33

Célula 4,6-4,7 vezes mais longa que larga, 180,6291,9 $\mu \mathrm{m}$ compr., 37,8-63 $\mu \mathrm{m}$ larg., oblonga-elíptica, margens laterais levemente convexas, margem apical truncada-arredondada, cloroplasto axial, 7-8 pirenóides distribuídos longitudinalmente, parede celular lisa, ou às vezes finamente pontuada.

Material examinado: BRASIL. PARANÁ: Foz do Iguaçu, Parque Nacional do Iguaçu, Rio São João, 25-IX-2008, J.C. Bortolini 2 (UNOP); idem, 25-IX2008, J.C. Bortolini 3 (UNOP).

Ocorrência no Paraná: Primeira citação da espécie.

\section{Octacanthium (Hansgirg) Compère}

Octacanthium mucronulatum (Nordstedt) Compère var. mucronulatum, Nova Hedwigia 112: 505. 1996 S Staurodesmus mucronulatus (Nordstedt) Compère, Táxon 25(2-3): 360. 1976.

Figura 34

Célula 1,2-1,5 vezes mais larga que longa, 29,5$36,9 \mu \mathrm{m}$ compr., 43,4-44,2 $\mu \mathrm{m}$ larg., istmo 8,2-9,8 $\mu \mathrm{m}$ larg., 2,4-3,2 $\mu \mathrm{m}$ esp., semicélula elíptico fusiforme, margem apical convexa, com 2 espinhos curtos em cada ápice, margens laterais levemente convexas, ângulos basais com espinhos curtos, reduzidos a mucros, levemente convexos em direção a semicélula oposta, constrição mediana profunda, seno mediano fechado próximo ao istmo e aberto em direção aos mucros, parede celular finamente pontuada.

Material examinado: BRASIL. PARANÁ: Foz do Iguaçu, Parque Nacional do Iguaçu, Rio São João, 16-VI-2008, N.C. Bueno 1067 (UNOP); idem, 28VIII-2008, N.C. Bueno 1078 (UNOP).

Ocorrência no Paraná: Rio São Francisco Falso, Município de Santa Helena (Biolo et al. 2008).

\section{Pleurotaenium Nägeli emend. Grönblad}

Pleurotaenium ehrenbergii (Brébisson) De Bary var. ehrenbergii, Untersuch. Fam. Conjug.: 75. $1858 \equiv$ Docidium ehrenbergii Brébisson in Ralfs, Brit. Desm.: 157. 1848.

Figura 35

Célula 10,3-17, 7 vezes mais longa que larga,
522,9-676,2 $\mu \mathrm{m}$ compr., 29,4-65,1 $\mu \mathrm{m}$ larg., 25,2$29,4 \mu \mathrm{m}$ istmo, cilíndrica, constrição mediana rasa, margens laterais retilíneas e onduladas próximo à região mediana, ápice truncado ornado com grânulos, parede celular finamente pontuada com vários pirenóides distribuídos ao longo das semicélulas.

Material examinado: BRASIL. PARANÁ: Foz do Iguaçu, Parque Nacional do Iguaçu, Rio São João, 16-VI-2008, N.C. Bueno 1067 (UNOP); idem, 28-VIII-2008, N.C. Bueno 1077 (UNOP); idem, 28-VIII-2008, N.C. Bueno 1078 (UNOP); idem, 28-VIII-2008, N.C. Bueno 1079 (UNOP); idem, 28-VIII-2008, N.C. Bueno 1082 (UNOP); idem, 25-IX-2008, J.C. Bortolini 1 (UNOP); idem, 25-IX2008, J.C. Bortolini 2 (UNOP); idem, 25-IX-2008, J.C. Bortolini 3 (UNOP); idem, 28-XI-2008, J.C. Bortolini 18 (UNOP).

Ocorrência no Paraná: Restinga de Pontal do Sul, Município de Paranaguá (Cecy 1993); Reservatório de Iraí, Município de Tijucas do Sul, (Cetto et al. 2004); Reservatório de Salto do Vau, Município de União da Vitória (Felisberto \& Rodrigues 2008); Rio São Francisco Falso, Município de Santa Helena (Biolo et al. 2008).

Spondylosium Brébisson ex Kützing

Chave para identificação dos materiais de Spondylosium estudados

1. Células unidas pela justaposição das semicélulas ... S. planum

1. Células unidas por processos cilíndricos da margem apical das semicélulas

S. pulchrum var. pulchrum

Spondylosium planum (Wolle) W. West \& G. West, Jour. Linn. Soc., ser. Bot. 40: 430. 1912 $\equiv$ Sphaerozosma pulchrum Bailey var. planum Wolle, Desm. U.S.: 29. 1884.

Figura 36

Célula 1,1 vezes mais longa que larga, 9,810,5 $\mu \mathrm{m}$ compr., 9,0-12,6 $\mu \mathrm{m}$ larg., 5,7 $\mu \mathrm{m}$ istmo, oblonga, margens laterais arredondadas, margens superior e inferior retas, filamento sem bainha de mucilagem, constrição mediana profunda, seno mediano aberto, células unidas pela justaposição das margens superiores das semicélulas, parede celular lisa, cloroplasto axial, 1 pirenóide por semicélula.

Material examinado: BRASIL. PARANÁ: Foz do 

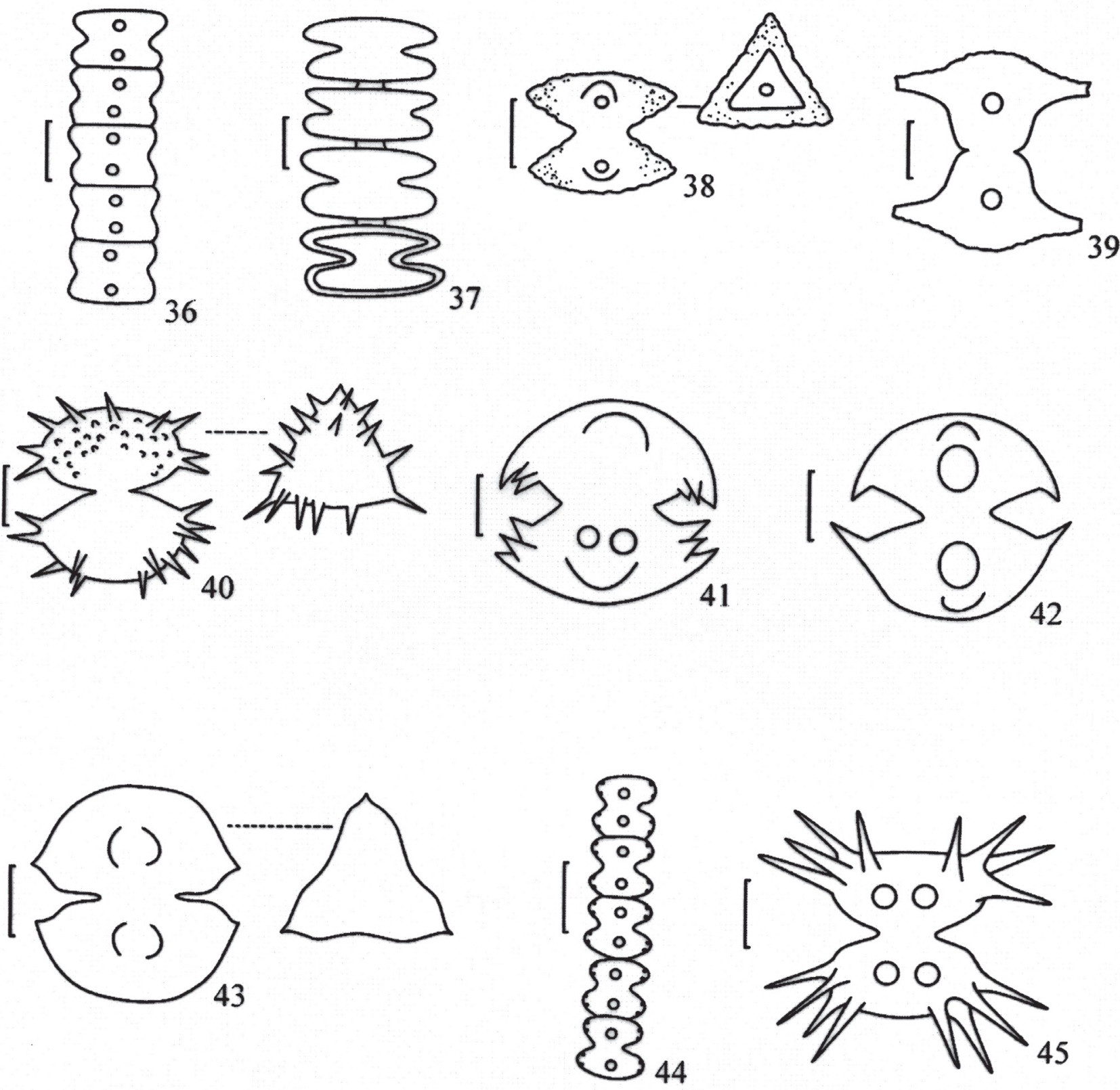

Figuras 36-45. Espécies de desmídias do Rio São João. 36. Spondylosium planum. 37. Spondylosium pulchrum var.pulchrum. 38. Staurastrum dilatatum var. dilatatum. 39. Staurastrum margaritaceum. 40. Staurastrum minnesotense var. minnesotense. 41. Staurastrum trifidum var. glabrum f. tortum. 42. Staurodesmus convergens var. laportei. 43. Staurodesmus lobatus var. ellipticus f. minor. 44. Teilingia granulata. 45. Xanthidium antilopaeum. Barras de escala $=10 \mu \mathrm{m}$, exceto figuras $37,45=25 \mu \mathrm{m}$.

Figures 36-45. Species of desmids from the São João River. 36. Spondylosium planum. 37. Spondylosium pulchrum var.pulchrum. 38. Staurastrum dilatatum var. dilatatum. 39. Staurastrum margaritaceum. 40. Staurastrum minnesotense var. minnesotense. 41. Staurastrum trifidum var. glabrum f. tortum. 42. Staurodesmus convergens var. laportei. 43. Staurodesmus lobatus var. ellipticus f. minor. 44. Teilingia granulata. 45. Xanthidium antilopaeum. Scales bars $=10 \mu \mathrm{m}$, except figures $37,45=25 \mu \mathrm{m}$. 
Iguaçu, Parque Nacional do Iguaçu, Rio São João, 16-VI-2008, N.C. Bueno 1066 (UNOP).

Ocorrência no Paraná: Reservatório de Iraí, Município de Tijucas do Sul (Cetto et al. 2004); Reservatório de Salto do Vau, Município de União da Vitória (Felisberto \& Rodrigues 2008).

Spondylosium pulchrum (Bailey) Archer var. pulchrum, in Pritchard's Infusoria 4: 724. 1861 $\equiv$ Sphaerozosma pulchrum Bailey in Ralfs, Brit. Desm.: 209, pl. 35, fig. 2. 1848.

Figura 37

Célula 1,6-2,3 vezes mais larga que longa, 27,339,9 $\mu \mathrm{m}$ compr., 63-67,2 $\mu \mathrm{m}$ larg., 16,8-23,1 $\mu \mathrm{m}$ istmo, oblonga, filamentos retos ou torcidos, semicélulas unidas por processos cilíndricos da margem apical da célula, constrição mediana profunda, seno mediano aberto, margens laterais arredondadas, margem apical com uma pequena elevação originando $\mathrm{o}$ processo cilíndrico, ângulos basais arredondados, parede celular lisa, 1 pirenóide por semicélula.

Material examinado: BRASIL. PARANÁ: Foz do Iguaçu, Parque Nacional do Iguaçu, Rio São João, 16-VI-2008, N.C. Bueno 1066 (UNOP); idem, 16VI-2008, N.C. Bueno 1068 (UNOP).

Ocorrência no Paraná: Rio Tibagi, nordeste do estado do Paraná (Bittencourt-Oliveira 1993a); Rio São Francisco Falso, Município de Santa Helena (Biolo et al. 2008).

\section{Staurastrum Meyen ex Ralfs}

Chave para identificação dos materiais de Staurastrum estudados

\section{Parede celular ondulada}

2. Semicélulas obtrapeziformes a elípticas S. margaritaceum

2. Semicélulas subelípticas S. dilatatum var. dilatatum

1. Parede celular lisa

3. Margem apical sem espinhos, margens laterais ornadas com 3 espinhos curtos, voltados para a outra semicélula

S. trifidum var. glabrum f. tortum

3. Margem apical com espinhos, margens laterais ornadas com 2 espinhos ligeiramente voltados para a semicélula oposta

S. minnesotense var. minnesotense

Staurastrum dilatatum (Ehrenberg) Ralfs var. dilatatum, Brit. Desm.: 133, pl. 21, fig. 8. 1848. Figura 38

Célula 1,0 vezes mais longa que larga, ou tão longa quanto larga, 20,5-23,4 $\mu \mathrm{m}$ compr., 19,6-21,8 $\mu \mathrm{m}$ larg., 5,7-6,4 $\mu \mathrm{m}$ istmo, semicélulas subelípticas, margens laterais côncavas, margem apical convexa, constrição mediana profunda, seno mediano aberto, ângulos arredondados, grânulos dispostos ao redor dos ângulos e pela célula, parede celular finamente granulosa, vista apical 3-angular, margens côncavas entre os ângulos arredondados, 1 pirenóide por semicélula.

Material examinado: BRASIL. Paraná: Foz do Iguaçu, Parque Nacional do Iguaçu, Rio São João, 28-VIII-2008, N.C. Bueno 1077 (UNOP).

Ocorrência no Paraná: Rio São Francisco Falso, Município de Santa Helena (Biolo et al. 2008);

Staurastrum margaritaceum (Ehrenberg)

Meneghini, Linnaea 14: 227. 1840 三 Pentasterias

margaritacea Ehrenberg, Infus.: 144: 15. 1838.

Figura 39

Célula 1,5-1,7 vezes mais longa que larga, sem considerar os processos, 36,9-39,9 $\mu \mathrm{m}$ compr., 21,325,2 $\mu \mathrm{m}$ larg.(sem proc.), 9,0-10,5 $\mu \mathrm{m}$ istmo, 5,7-7,3 $\mu \mathrm{m}$ proc., obtrapeziforme a transversalmente elíptica, constrição mediana profunda, seno mediano aberto, 6 processos robustos, truncados, com suas extremidades lisas ou em alguns casos, 3-denticuladas, margens serreadas, margens laterais levemente convexas, lisas, margem superior convexa e truncada, parede celular lisa, cloroplasto contendo 1 pirenóide por semicélula.

Material examinado: BRASIL. PARANÁ: Foz do Iguaçu, Parque Nacional do Iguaçu, Rio São João, 25-IX-2008, J.C. Bortolini 1 (UNOP); idem, 30-IV2009, J.C. Bortolini 47 (UNOP).

Ocorrência no Paraná: Represa do Rio Passaúna, Município de Araucária (Cecy et al. 1997); Reservatório de Salto do Vau, Município de União da Vitória (Felisberto \& Rodrigues 2008); Rio São Francisco Falso, Município de Santa Helena (Biolo et al. 2008).

Staurastrum minnesotense Wolle var. minnesotense, Bull. Torr. Bot. Club 12(1): 6, pl. 47, fig. 7-8. 1885.

Figura 40

Célula 1,1-1,2 vezes mais longa que larga, 34,4$36,4 \mu \mathrm{m}$ compr. (sem esp.), 28,7-29,9 $\mu \mathrm{m}$ larg. (sem esp.), 5,7-7,3 $\mu \mathrm{m}$ istmo, 3,2-6,5 $\mu \mathrm{m}$ esp., semicélula 
transversalmente elíptica, constrição mediana profunda, seno mediano aberto, margem apical e lateral convexas, ângulos arredondados, ornados com 2 espinhos ligeiramente voltados para a semicélula oposta, região superior das semicélulas ornadas com espinhos, parede celular pontuada.

Material examinado: BRASIL. PARANÁ: Foz do Iguaçu, Parque Nacional do Iguaçu, Rio São João, 16-VI-2008, N.C. Bueno 1068 (UNOP).

Ocorrência no Paraná: Rio São Francisco Falso, Município de Santa Helena (Biolo et al. 2008).

Staurastrum trifidum Nordstedt var. glabrum Langerheim f. tortum Börgesen, Vidensk. Medd. Dansk Naturh. Foren.: 49, pl. 5, fig. 56. 1890. Figura 41

Célula 1,0-1,1 vezes mais longa que larga, 30,732,4 $\mu \mathrm{m}$ compr., 27,5-29,9 $\mu \mathrm{m}$ larg. (sem esp.), 6,49,7 $\mu \mathrm{m}$ istmo, 4-7,2 $\mu \mathrm{m}$ esp., semicélula elíptica e assimétrica, margem apical acentuadamente convexa, margens laterais mais ou menos convexas, ângulos laterais ornados com 3 espinhos curtos, voltados para a outra semicélula, sendo 2 deles mais superiores e o terceiro entre os dois, constrição mediana profunda, seno mediano aberto, acutangular, parede celular lisa, cloroplasto axial, pirenóides não observados.

Material examinado: BRASIL. PARANÁ: Foz do Iguaçu, Parque Nacional do Iguaçu, Rio São João, 28-VIII-2008, N.C. Bueno 1078 (UNOP); idem, 25IX-2008, J.C. Bortolini 1 (UNOP); idem, 25-IX2008, J.C. Bortolini 2 (UNOP); idem, 22-I-2009, J.C. Bortolini 28 (UNOP).

Ocorrência no Paraná: Primeira citação da espécie.

\section{Staurodesmus Teiling}

Chave para identificação dos materiais de Staurodesmus estudados

1. Semicélula elípticas com 1 espinho curto, curvado, convergente, na metade da semicélula

S. convergens var. laportei

1. Semicélula oblonga a elíptica com 1 diminuto espinho na metade da semicélula

S. lobatus var. ellipticus f. minor

Staurodesmus convergens (Ehrenberg) Teiling var. laportei Teiling, Ark. Bot. 6: 588, pl. 25, fig. 4-7; pl. 26, fig. 1-3. 1967.

Figura 42
Célula 1,0 vez mais longa que larga, ou tão longa quanto larga, 23,5-24,7 $\mu \mathrm{m}$ compr.(sem esp.), 28,8-29,1 $\mu \mathrm{m}$ larg., 6,1-8,1 $\mu \mathrm{m}$ istmo, 7,2-10,3 $\mu \mathrm{m}$ esp., semicélulas elípticas, margem apical e basal convexas, ângulos arredondados com 1 espinho curto, curvado, convergente, inserido mais ou menos na metade da semicélula, ápice acuminado, constrição mediana profunda, seno mediano amplamente aberto, porém estreito próximo ao istmo, parede celular lisa, hialina, cloroplasto axial, 1 pirenóide por semicélula, vista apical e lateral não observadas.

Material examinado: BRASIL. PARANÁ: Foz do Iguaçu, Parque Nacional do Iguaçu, Rio São João, 28-VIII-2008, N.C. Bueno 1078 (UNOP); idem, 16VI-2008, N.C. Bueno 1068 (UNOP).

Ocorrência no Paraná: Primeira citação da espécie.

Staurodesmus lobatus (Börgesen) Bourrelly var. ellipticus (Fritsch \& Rich) Teiling f. minor (G. Smith) Teiling, Ark. Bot. 6(11): 586. $1967 \equiv$ Cosmarium contractum Kirchner var. papillatum West \& West f. minor G.M. Smith, Trans. Wis. Acad. Sci. Arts Lett. 20: 345. 1922.

Figura 43

Célula 1,1 vezes mais longa que larga, 31-34,2 $\mu \mathrm{m}$ compr., 27,1-29,9 $\mu \mathrm{m}$ larg., 5,7-7,2 $\mu \mathrm{m}$ istmo, semicélula oblongo a elíptico, margens apical e lateral convexas e lisas, ângulos arredondados com 1 pequeno espinho, constrição mediana profunda, seno mediano aberto, vista apical 3-angular, parede celular finamente pontuada.

Material examinado: BRASIL. PARANÁ: Foz do Iguaçu, Parque Nacional do Iguaçu, Rio São João, 25-IX-2008, J.C. Bortolini 1 (UNOP).

Ocorrência no Paraná: Represa do Rio Passaúna (Picelli-Vicentim et al. 2001); Rio São Francisco Falso, Município de Santa Helena (Biolo et al. 2008).

\section{Teilingia Bourrelly}

Teilingia granulata (Roy \& Bisset) Bourrelly, Rev. Alg. n. s. 7: 190. $1964 \equiv$ Sphaerozosma granulatum J. Roy \& Bisset, J. Bot. 24: 242. 1886.

Figura 44

Célula 1,1 vezes mais longa que larga, 8,19,7 $\mu \mathrm{m}$ compr., 7,2-9,4 $\mu \mathrm{m}$ larg., 2,4 $\mu \mathrm{m}$ istmo, filamentos não torcidos, semicélulas oblongas, constrição mediana profunda, seno mediano aberto, margens laterais lisas e arredondadas, com pequenos grânulos beirando-a, ápice truncado, ligando uma 
célula a outra, parede celular lisa, cloroplasto axial, 1 pirenóide por semicélula.

Material examinado: BRASIL. PARANÁ: Foz do Iguaçu, Parque Nacional do Iguaçu, Rio São João, 25-IX-2008, J.C. Bortolini 1 (UNOP).

Ocorrência no Paraná: Primeira citação da espécie.

Xanthidium Ehrenberg emend. Ralfs

Xanthidium antilopaeum (Brébisson) Kützing, Sp. Alg.: 177. 1849 E Cosmarium antilopaeum Brébisson in Meneghini, Syn. Desm.: 218. 1840. Figura 45

Célula 1,1 vezes mais longa que larga, 73,5-75,3 $\mu \mathrm{m}$ compr. (sem esp.), 63-64 $\mu \mathrm{m}$ larg. (sem esp.), 27,3-29,1 $\mu \mathrm{m}$ istmo, 16,8-21 $\mu \mathrm{m}$ esp., semicélulas elípticas a hexagonais, margem superior reta ou levemente convexa, margens laterais arredondadas, constrição mediana profunda, seno mediano aberto, acutangular, arredondado próximo ao istmo, 1 par de espinhos em cada ângulo superior, 1 par de espinhos em cada ângulo inferior, espinhos simples, longos, retos com a base mamiliforme, região central das semicélulas sem espinhos, parede celular finamente pontuada.

Material examinado: BRASIL. ParanÁ: Foz do Iguaçu, Parque Nacional do Iguaçu, Rio São João, 28-X-2008, J.C. Bortolini 11 (UNOP).

Ocorrência no Paraná: Primeira citação da espécie.

Dos 44 táxons de desmídias registrados no presente estudo $25 \%$ compreenderam representantes do gênero Cosmarium, contribuindo, portanto, com a maior parcela da biodiversidade total de espécies. Os gêneros com menor representatividade foram Actinotaenium, Bambusina, Desmidium, Netrium, Octacanthium, Pleurotaenium e Teilingia representados cada um por apenas uma espécie, que juntos somaram 7\% do total. Em relação à freqüência de ocorrência dos táxons nas amostragens, Desmidium cylindricum, Gonatozygon kinahanii e Pleurotaenium ehrenbergi apresentaram a melhor distribuição, $41 \%$, $38 \%$ e $25 \%$ de presença respectivamente. De todos os registros, dez táxons foram mencionados pela primeira vez para o Estado do Paraná.

Espacialmente, as três estações de amostragem constituíram-se em locais de grande importância para o desenvolvimento do grupo, no entanto, a maior contribuição para a biodiversidade ocorreu na estação 1 , provavelmente devido a presença de diversas espécies de macrófitas aquáticas no local.
Já em relação ao atributo temporal, os meses de junho e julho de 2008 e maio de 2009 foram os que apresentaram maior biodiversidade de desmídias.

Cabe ressaltar que apesar do ambiente estudado ser lótico, grande biodiversidade de Zygnemaphyceae foi registrada, comprovando a distribuição cosmopolita do grupo. As citações pioneiras enfatizam, entretanto, a clara escassez de estudos sobre a taxonomia e distribuição geográfica do grupo neste tipo de ambiente. Logo, cabe ressaltar neste trabalho o quão importante são os estudos realizados em ecossistemas lóticos, e que o conhecimento ficológico destes ambientes é o instrumento primordial para o entendimento da sua dinâmica.

\section{Agradecimentos}

Ao Instituto Chico Mendes de Conservação da Biodiversidade na pessoa do Diretor do Parque Nacional do Iguaçu, pelas facilidades concedidas para a realização dos estudos. Ao Sisbio pela autorização concedida para realização da pesquisa na Unidade de Conservação (13134-2). A Fundação Araucária (Chamada 14/2008) e Convênio Fundação Araucária 225/08 (Bolsa de Mestrado).

\section{Literatura citada}

Andrade, R.M. \& Rachou, R. 1954. Levantamento preliminar de organismos planctônicos em alguns criadouros de Anopheles darlingi, no sul do Brasil. Revista Brasileira de Malariologia 6: 481-96.

Bicudo, C.E.M. \& Menezes, M. 2006. Gêneros de algas de águas continentais do Brasil: Chave para identificação e descrições. RiMa, São Carlos.

Biolo, S., Siqueira, N.S. \& Bueno, N.C. 2008. Desmidiaceae (exceto Cosmarium) de um tributário do Reservatório de Itaipu, Paraná, Brasil. Hoehnea 35: 145-162.

Bittencourt-Oliveira, M.C. 1993a. Ficoflórula do Rio Tibagi, Estado do Paraná, Brasil I: Desmídias Filamentosas e Gêneros Gonatozygon, Penium, Pleurotaenium e Tetmemorus (Zygnemaphyceae). Semina, Ciências Biológicas 14: 61-73.

Bittencourt-Oliveira, M.C. 1993b. Ficoflórula do Rio Tibagi, Estado do Paraná, Brasil III: gêneros 
Actinotaenium, Cosmarium e Staurodesmus (Zygnemaphyceae). Semina, Ciências Biológicas 14: 86-95.

Bittencourt-Oliveira, M.C. \& Castro, A.A.J. 1993. Ficoflórula do Rio Tibagi, Estado do Paraná, Brasil, II: gênero Closterium (Zygnemaphyceae). Semina, Ciências Biológicas 14: 74-85.

Bittencourt-Oliveira, M.C. \& Mecenas, P.R. 1994. Ficoflórula do Rio Tibagi, Estado do Paraná, Brasil, IV: gêneros Micrasterias, Staurastrum e Xanthidium (Zygnemaphyceae). Semina, Ciências Biológicas 15: 133-152.

Bittencourt-Oliveira, M.C. 2002. A comunidade fitoplanctônica do Rio Tibagi: uma abordagem preliminar de sua diversidade. In: M.M. Medri, E. Bianchini, O.A. Shibatta \& J.A. Pimenta (orgs.). A Bacia do rio Tibagi. FUEL, Londrina.

Borges, P.A.F., Train, S. \& Rodrigues, L.C. 2008. Estrutura do fitoplâncton em curto período de tempo em um braço do reservatório de Rosana (ribeirão do Corvo, Paraná, Brasil). Acta Scientiarium, Biological Sciences 30: 57-65.

Bortolini, J.C., Moresco, C., Siqueira, N.S., Biolo, S. \& Bueno, N.C. 2009. Closterium Nitzsch ex Ralfs (Desmidiaceae) em um lago artificial urbano, Paraná, Brasil. Hoehnea 36: 445-454.

Cavati, B. \& Fernandes, V.O. 2008. Algas perifíticas em dois ambientes do baixo rio Doce (Lagoa Juparanã e rio Pequeno - Linhares, Espírito Santo, Brasil): variação espacial e temporal. Acta Scientiarum, Biological Sciences 30: 439-448.

Cecy, I.I.T. 1986. Estudo das algas microscópicas (Nostocophyta, Euglenophyta, Chrysophyta e Chlorophyta) do Lago do Parque Barigui, em Curitiba, Estado do Paraná, Brasil. Arquivos de Biologia e Tecnologia 29: 383-405.

Cecy, I.I.T. 1993. Expressões morfológicas observadas em Pleurotaenium ehrenbergii (Brébisson) De Bary, procedentes da Restinga de Pontal do Sul, Município de Paranaguá, Paraná. Estudos de Biologia 30: 5-20.

Cecy, I.I.T., Moreira, I.M.V. \& Hohmann, E. 1976. Estudo Ficológico e químicobacteriológico da água do tanque do passeio público de Curitiba, Estado do Paraná, Brasil. Boletim Museu Botânico Municipal 25: 1-37.

Cecy, I.I.T., Silva, S.R.V.F. \& Boccon, R. 1997. Fitoplâncton da Represa do Rio Passaúna, Município de Araucária, Estado do Paraná. I Divisão Chlorophyta-Família Desmidiaceae. Estudos de Biologia 41: 5-32.
Cetto, J.M., Leandrini, J.A., Felisberto, S.A. \& Rodrigues, L. 2004. Comunidade de algas perifíticas no reservatório de Iraí, Estado do Paraná, Brasil. Acta Scientiarium, Biological Sciences 26: 1-7.

Felisberto, S.A. 2003. Composição e abundância de desmídias perifiticas caracterizando reservatórios e suas regiões ao longo do eixo rio-barragem. Dissertação de Mestrado, Universidade Estadual de Maringá, Maringá.

Felisberto, S.A. \& Rodrigues, L. 2007. Gênero Closterium (Closteriaceae) na comunidade perifítica do Reservatório de Salto do Vau, sul do Brasil. Iheringia, série Botânica 62: 45-54.

Felisberto,S.A.\&Rodrigues,L.2008.Desmidiaceae, Gonatozygaceae e Mesotaeniaceae na comunidade perifítica do Reservatório de Salto do Vau (Bacia do Rio Iguaçu, PR). Hoehnea 35: 235-254.

Lozovei, A.L. \& Luz, E. 1976. Díptera Culicidae em Curitiba e arredores 2: Alimentação. Arquivos de Biologia e Tecnologia 19: 43-83.

Lozovei, A.L. \& Hohmann, E. 1977. Principais gêneros de microalgas em biótopos de larvas de mosquito de Curitiba, Estado do Paraná, Brasil, 3: Levantamento e constatação da ecologia. Acta Biológica Paranaense 6: 123-152.

Melo, S., Souza, K.F., Rebelo, S.R.M. \& Sophia, M.G. 2009. Gêneros Euastrum Ehrenberg ex Ralfs e Micrasterias C. Agardh (Conjugatophyceae-Desmidiaceae) de dois ambientes amazônicos de águas pretas (Manaus, Amazonas-Brasil). Acta Amazonica 39: 13-20.

Moresco, C., Biolo, S. \& Bueno, N.C. 2009. O gênero Micrasterias Agardh ex Ralfs (Desmidiaceae, Zygnemaphyceae) em um lago artificial urbano, Paraná, Brasil. Hoehnea 36: 349-358.

Picelli-Vicentim, M.M. 1984. Desmídeas (Zygnemaphyceae) planctônicas do Parque Regional do Iguaçu, Curitiba, Estado do Paraná, Brasil: contribuição ao levantamento. Dissertação de Mestrado, Universidade Federal do Paraná, Curitiba.

Picelli-Vicentim, M.M., Treuersch, M. \& Domingues, L.L. 2001. Fitoplâncton da Represa do Passaúna, Estado do Paraná, Brasil. Hoehnea 28: 53-76.

Salamuni, R., Salamuni, E., Rocha, L.A. \& Rocha, A.L. 2002. Parque Nacional do Iguaçu, PR: Cataratas de fama mundial. In: C. Schobbenhaus, D.A. Campos, E.T. Queiroz, M. Winge \& 
M.L.C. Berbert-Born (eds.). Sítios Geológicos e Paleontológicos do Brasil. DNPM/CPRM - Comissão Brasileira de Sítios Geológicos e Paleobiológicos, Brasília.

Silva, S.R.V.F. \& Cecy, I.I.T. 2004. Desmídias (Zygnemaphyceae) da área de abrangência da Usina Hidrelétrica de Salto Caxias, Paraná, Brasil, I: Gênero Cosmarium. Iheringia, série Botânica 59: 13-26.

Soares, M.C., Sophia, M.G. \& Huszar, V.L.M. 2007. Phytoplankton flora of two rivers in Southeast Brazil-Paraibuna and Pomba Rivers, Minas Gerais.
Revista Brasileira de Botânica 30: 433-450.

Sophia, M.G., Dias, I.C.A. \& Araújo, A.M. 2005. Chlorophyceae and Zygnematophyceae from the Turvo State Forest Park, state of Rio Grande do Sul, Brazil. Iheringia 60: 25-47.

Stankiewicz, E.H. 1980. Flórula no conteúdo estomacal do Pseudocurimata gilberti (Quoy e Gaimard 1824). Dissertação de Mestrado, Universidade Federal do Paraná, Curitiba.

Stankiewicz, E.H., Andrade, L.F. \& Domingues, L.L. 1981. Levantamento ficológico do Rio Iguaçu: algas unicelulares, 1. Surehma 1: 1-76. 